

\section{Sumário}

Dossiê TEMÁTICO: NOVOS INSTITUTOS JURÍDICOS DE LICITAÇÕES E CONTRATOS 17

I. LicitaÇõEs E CONTRATOS PÚBLICOS: PARTE GERAL. 18

INTEGRATED CONTRACT IN LAW 14.133/2021: NEW LAW, SAME PROBLEMS? A STUDY OF COMPARATIVE LAW .20

Paulo Afonso Cavichioli Carmona, Bruno Ribeiro Marques e Odilon Cavallari

Reajustamento de preços na Nova Lei de Licitações e Contratos Administrativos BRASILEIRA: O "Princípio" Da ANUALIDAde.

Ricardo Silveira Ribeiro e Bráulio Gomes Mendes Diniz

A nova Lei de Licitações, as encomendas tecnológicas e o diálogo competitivo .61 André Dias Fernandes e Débora de Oliveira Coutinho

LiCITAÇÕES, CONTRATOS E O IMPULSO À APRENDIZAGEM PROFISSIONAL: UM ESTUDO SOBRE A CONTRATAÇÃo de APRENDizes no ESTAdo do AMAZONAS, BRAsIL

Emerson Victor Hugo Costa de Sá, Natasha Yasmine Castelo Branco Donadon e Mauro Augusto Ponce de Leão Braga

Licitações, contratos e Modelo Brasileiro de Processo: notas sobre a viabilidade DA UTILIZAÇÃo DE FERRAMENTAS PROCESSUAIS PARA CONFERIR MAIOR EFICIÊNCIA ÀS AQUISIÇÕES PÚBLICAS

Claudio Madureira e Carlos André Luís Araujo

RESOlUÇão DE CONFLITOS COM A ADMINISTRAÇÃo PÚBLICA E A NOVA LEI DE LICITAÇÕES E CONTRATOS: REFORÇO DOS MEIOS ALTERNATIVOS..

Clarissa Sampaio Silva e Danielle Maia Cruz

A Adesão do Brasil ao Acordo sobre Contratações Públicas da OMC: entre tabus e DIFICULDADES REAIS.

Eduardo Ferreira Jordão e Luiz Filippe Esteves Cunha

II. Accountability e controle

A LEI N. ${ }^{\circ}$ 14.133/2021 E OS NOVOS LIMITES do CONTROLE EXTERNO: A NECESSÁRIA DEFERÊNCIA dos Tribunais de Contas em prol da Administração Pública .................................. 162 Ricardo Schneider Rodrigues

O CONTROLE DAS CONTRATAÇÕES PÚBliCAS E A NOVA LEI DE LICITAÇÕES: O QUE HÁ DE Novo? 183

Leandro Sarai, Flávio Garcia Cabral e Cristiane Rodrigues Iwakura 
Programa de compliance como exigênCia em licitações: ANálises EM Prol da QUALIFICAÇÃo DO PROCESSO LICITATÓRIO NO CONTEXTO DA LEI 14.133/2021.

Cristian Ricardo Wittmann e Anayara Fantinel Pedroso

A NOVA REALIDAde bRASILEIRA DE NECESSIDADE DE PROGRAMAS DE INTEGRIDADE DAS PESSOAS JURÍDICAS LICITANTES EM PROCESSOS LICITATÓRIOS DA ADMINISTRAÇÃO PÚBLICA 227

Fernando Silva Moreira dos Santos e Luiz Fernando de Oriani e Paulillo

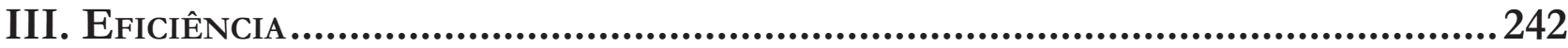

Efficiency contracts in the New Brazilian Procurement Law: conceptual FRAMEWORK AND INTERNATIONAL EXPERIENCE

Floriano de Azevedo Marques Neto, Hendrick Pinheiro e Tamara Cukiert

A gestão de riscos como instrumento para a aplicação efetiva do Princípio Constitucional dA EFICIÊNCIA.

Rafael Rabelo Nunes, Marcela Teixeira Batista Sidrim Perini e Inácio Emiliano Melo Mourão Pinto

IV. Contratação PÚblica No Direito ESTrangeiro

LA ADQUisición de VACUNAS CONTRA LA COVID-19 POR COLOMBIA: ENTRE LA CONFIDENCIALIDAD Y LA FALTA DE TRANSPARENCIA. 284

Gressy Kareny Rojas Cardona e David Mendieta

LA DISCRIMINACIÓN EX POST DE LOS OFERENTES DE UNA LICITACIÓN PÚBLICA COMO INFRACCIÓN ADMINISTRATIVA Y DE LIBRE COMPETÊNCIA 312 Jaime Arancibia Mattar

LA DISCRIMINACIÓN EX POST DE LOS OFERENTES DE UNA LICITACIÓN PÚBLICA COMO INFRACCIÓN ADMINISTRATIVA Y DE LIBRE COMPETÊNCIA..........................................................332 Udochukwu Uneke Alo, Obiamaka Adaeze Nwobu e Alex Adegboye

Outros Temas 348

I. Políticas públicas e institucionalidade

¿Existe El derecho humano a la identidad Cultural de los Migrantes en El Derecho INTERNACIONAL? 351

Glorimar Alejandra Leon Silva e Juan Jorge Faundes

El acceso a la justicia y el debido proceso ante el Tribunal Constitucional y la CorTe Suprema: dos NOCIONES DEL CONTENCIOSO ADMINISTRATIVO CHILENO .384 Pedro Harris Moya 
“Ministrocracia” E DECISÕES INDIVIDUAis CONTRAditórias No Supremo Tribunal FEDERAI

Ulisses Levy Silvério dos Reis e Emilio Peluso Neder Meyer

A POlÍtica de INOVAÇÃo COMO INSTRUMENTO DE REDUÇÃo DAS DESIGUALDADES REGIONAIS NO BRASIL

Caroline Viriato Memória e Uinie Caminha

Conflitos de Competência E A JudicializaÇão da Saúde no Federalismo Brasileiro.447 Jorge Leal Hanai, Luis Antônio Abrantes e Luiz Ismael Pereira

O Ministério Público no enfrentamento dos Reflexos da CRise da Covid-19: UMA

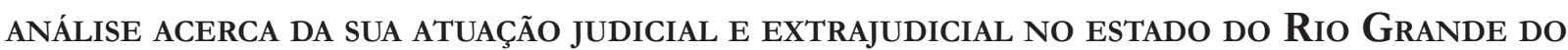
NorTE

Raquel Maria da Costa Silveira, Ana Mônica Medeiros Ferreira, Flávio Luiz Carneiro Cavalcanti e Haroldo Helinski Holanda

A CONSAgRaÇão CONSTITUCIONAL DA POlítica FALIMENTAR

Nuno de Oliveira Fernandes

II. Políticas públicas, grupos vulneráveis e litígios estruturais

LAS LIMITACIONES A LOS DERECHOS DE LOS GRUPOS VULNERABLES Y LOS SUJETOS DE ESPECIAL PROTECCIÓN DURANTE LA PANDEMIA Mary Luz Tobón Tobón

LitígIOS ESTRUTURAIS E A PROTEÇÃO DOS DIREITOS DOS POVOS INDÍGENAS DURANTE A PANDEMIA DE Covid-19: CONTRIBUições do ICCAL

Ana Carolina Lopes Olsen e Bianca M. Schneider van der Broocke

EPISTEMICÍDIO DAS NARRATIVAS NEGRAS E LITÍGIO ESTRUTURAL: INSTRUMENTOS EXTRAJUDICIAIS PARA DISSOLUÇÃO DO PROBLEMA NO SISTEMA EDUCACIONAL .......................................582

Vitor Fonsêca e Caroline da Silva Soares

Trajetórias E DiRETRIZES dAS POlíticas PÚbliCAS NACIONAIS PARA A POPULAÇão INFANTOJUVENIL EM SITUAÇÃO DE RUA...

Wânia Cláudia Gomes Di Lorenzo Lima, Cynthia Xavier de Carvalho e Maria Creusa de A. Borges

Emprendimiento como Fuente de Ingresos para las Víctimas del Conflicto Armado en el Marco de la Ley 1448 de Colombia. Reflexiones de la Implementación en el Valle del Cauca

Saulo Bravo García e Luz Marina Restrepo García

III. Políticas públicas e aÇão Restaurativa. 
JUSTIÇA RESTAURATIVA COMO AÇÃO COMUNICATIVA: EQUILÍBRIO ENTRE SISTEMA E MUNDO DA

Daniela Carvalho Almeida da Costa e Luciana Leonardo Ribeiro Silva de Araújo

JUSTIÇA RESTAURATIVA: ACORDOS E COOPERAÇÃO.................................................668

Samyle Regina Matos Oliveira e Selma Pereira de Santana 


\title{
¿Existe el derecho humano a la identidad cultural de los migrantes en el Derecho Internacional?*
}

\section{¿ls there a human right to cultural identity for migrants in the international law?}

\author{
Glorimar Alejandra Leon Silva***/ \\ Juan Jorge Faundes***
}

\section{Resumen}

El fenómeno migratorio y su globalización plantea, conjuntamente a otros temas de amplio tratamiento como el estatus mínimo de derechos, la cuestión del ejercicio del derecho a la identidad cultural de los migrantes. Pero $¿$ Existe realmente este derecho en el ámbito internacional a favor de estos grupos? Son varios los instrumentos de derechos humanos de los cuales se puede observar su desarrollo progresivo; y, no obstante, son frecuentes los casos en los que se deniega o delimita su amparo mediante la violación "normalizada" de derechos básicos en el trato desigual de las personas en función de su origen y sus costumbres. El objeto de este artículo es demostrar la existencia del derecho a la identidad cultural a favor de los migrantes en el ámbito internacional bajo un enfoque interpretativo de amplio espectro (con base al principio de igualdad y no discriminación) y bajo un enfoque interpretativo estricto (con base a la protección de las minorías). Para ello, revisaremos los principales instrumentos internacionales erigidos en la materia, atendiendo a las observaciones generales y demás resoluciones emanadas de los órganos creados para la vigilancia del cumplimiento de estos, junto a la doctrina más relevante y jurisprudencia internacional pertinente. Los resultados expuestos son: (i) una justificación normativa desde las fuentes del sistema universal de derechos humanos del derecho humano a la identidad de los migrantes; (ii) una justificación del derecho humano a la identidad de los migrantes en los sistemas regionales de derechos humanos, europeo e interamericano, verificada jurisprudencialmente. La metodología es de estudio dogmático de las fuentes normativas, revisión bibliográfica y verificación jurisprudencial.

Palabras clave: identidad cultural, derechos humanos, no discriminación, principio de igualdad, migrantes.

\section{Abstract}

The increase in the migratory phenomenon and its globalization is closely related to the exercise of the right to cultural identity of migrants. Does this right really exist in the international arena in favor of these groups? There are various human rights instruments from which the progressive develop- 
ment of this right can be observed; However, there are frequent cases in which their protection is denied or delimited through the "normalized" violation of basic rights in the unequal treatment of people based on their origin and customs. The purpose of this article is to demonstrate the existence of the right to cultural identity in favor of migrants at the international level under a broad-spectrum interpretative approach (based on the principle of equality and non-discrimination) and under a strict interpretative approach (with basis for the protection of minorities). To do this, we will review the main international instruments erected on the matter, considering the general observations and other resolutions emanating from the bodies created to monitor compliance with these, along with the most relevant doctrine. The results will be presented in two parts: the first dedicated to the review of the universal human rights system and the second dedicated to the review of regional systems. The methodology is the study of normative sources, bibliographic review and verification based on jurisprudential review.

Keywords: cultural identity, human rights, nondiscrimination, equality, migrants.

\section{Introducción}

$\mathrm{Al}$ fenómeno de la migración internacional -y su incremento a nivel mundial- se observan asociadas múltiples formas de discriminación basadas en lógicas de exclusión y segregación social ${ }^{1}$, debido a las características raciales, nacionalidad y estatus legal de los migrantes ${ }^{2}$. Tales discriminaciones son persistentes, a pesar de los derechos inherentes a la dignidad humana de las personas migrantes ${ }^{3}$. Este fenómeno y su globalización ha puesto en contacto más estrecho que nunca a diferentes culturas, grupos y personas en un momento en que cada una de ellas se esfuerza por preservar su propia identidad. Así, los referentes colectivos con los que los migrantes reconstruyen su identidad en la sociedad que los recibe están cargados con su experiencia de discriminación y rechazo por parte de la sociedad de acogida; y, en consecuencia, la experiencia migratoria -como experiencia de desarraigo-, se constituirá en sí misma en una base material

\footnotetext{
SOLÉ, Carlota; PARELLA, Sònia; ALARCÓN, Amado; BERGALLI, Valeria; GIBERT, Francesc. El impacto de la inmigración en la sociedad receptora. Revista Española de Investigaciones Sociológicas, España, 90, p. 31-157. 2000. p. 133; ORGANIZACIÓN INTERNACIONAL PARA LAS MIGRACIONES. Glosario sobre migración, 2006. Disponible en: http://publications. iom.int/system/files/pdf/iml_7_sp.pdf. Acceso: 3 mar. 2017. p. 329.

2 CRÉPEAU, François. Derechos humanos de los migrantes: Informe del Relator Especial sobre los derechos humanos de los migrantes, documento de las Naciones Unidas A/69/302, 2014. Disponible en: https://documents-dds-ny.un.org/doc/UNDOC/ GEN/N14/501/99/PDF/N1450199.pdf?OpenElement. Acceso: 13 mar. 2020.

3 CASTILLO, Luis. La relación entre los ámbitos normativos internacional y nacional sobre derechos humanos. Estudios Constitucionales, vol. 10, N² 2, p. 231-280. 2012. p. 233 y 234. Persona es todo ser humano según lo regula el Derecho Internacional moderno. Esta condición no resulta alterada independientemente de sus condiciones concretas. El artículo 24 de la CIPDTMYF reitera la personalidad de los migrantes. Ello también ha sido reiterado por la Corte Interamericana de Derechos Humanos en CORTE IDH. Opinión Consultiva OC-18/03 sobre Condición Jurídica y Derechos de los Migrantes Indocumentados (2003), 17 septiembre 2003 , Serie $A N^{\circ} 18$, párr. 72. En estos pronunciamientos se han reconocido a los migrantes -en cuanto tales- varios derechos, entre los que se pueden mencionar: la libertad de expresión, opinión, conciencia, el derecho de reunión y asociación, el derecho al debido proceso, el derecho a la vida e integridad física, el derecho a la vida privada y familiar. El Comité de Derechos Humanos, ha sostenido el ejercicio de los derechos reconocidos por el Pacto no se limita a los ciudadanos de los Estados parte, sino que su reconocimiento se extiende a todos los individuos presentes en el territorio o bajo la jurisdicción del Estado parte, independientemente de su nacionalidad (COMITÉ DE DERECHOS HUMANOS. Observación General No. 15: Comentarios generales adoptados por el Comité de los Derechos Humanos, la situación de los extranjeros con arreglo al Pacto, documento de las Naciones Unidas HRI/GEN/1/ Rev.7, 1986. Disponible en: http://hrlibrary.umn.edu/hrcommittee/Sgencom15.html. Acceso: 3 nov. 2020).

Según Aguilera, la noción de dignidad impide el empleo instrumental o como medio del ser humano (AGUILERA PORTALES, Rafael. Concepto y fundamento de los Derechos Humanos en la teoría jurídica contemporánea. En: AGUILAR CARVALLO, Gonzalo (editor). 60 años después: enseñanzas pasadas y desafíos futuros: Conmemoración de los 60 años de la Declaración Universal de Derechos Humanos y de la Declaración Americana de los Derechos y Deberes del Hombre. Santiago: Librotecnia, 2008. p. $17-75$. p. 31.
} 
para la configuración de nuevas identidades colectivas ${ }^{4}$. Y ello ocurre desde el mismo momento de su establecimiento en una sociedad determinada, incrementando su vulnerabilidad 5 .

Existe pues una relación entre la interacción cultural y los procesos de cambio cultural -incluso de conflicto cultural ${ }^{6}-$ que es propia de los procesos migratorios. Como lo muestra el caso europeo y, emergentemente, el de América Latina ${ }^{7}$, el fenómeno migratorio plantea, conjuntamente, la cuestión del ejercicio del derecho a la identidad cultural (DIC).

En el ámbito universal son varios los instrumentos internacionales de derechos humanos de los cuales se desprende el desarrollo progresivo del derecho a la identidad cultural como derecho humano. Pero, pese a la existencia de estas previsiones internacionales, son frecuentes los casos en los que se deniega o delimita (en el grado de la afectación) jurisprudencialmente el amparo de este derecho de los migrantes. Ello se traduce en la violación "normalizada" de derechos básicos en el trato desigual de las personas en función de su origen ${ }^{8}$ y sus costumbres. Por ello, el objeto de este estudio comprende, primero, las fuentes universales y regionales (europeas e interamericanas) de derechos humanos que justifican la existencia del derecho humano a la identidad cultural de los migrantes. Segundo, la revisión jurisprudencial de los respectivos tribunales de derechos humanos del Sistema Europeo y del Sistema Interamericano de Derechos Humanos, que hacen aplicación efectiva de este derecho. Así, la tesis de este estudio responderá afirmativamente a la pregunta: ¿existe el derecho humano a la identidad cultural de los migrantes en el Derecho Internacional?.

Los resultados del estudio son: (i) una justificación normativa desde las fuentes del sistema universal de derechos humanos del derecho humano a la identidad de los migrantes; (ii) una justificación del derecho humano a la identidad de los migrantes en los sistemas regionales de derechos humanos, europeo e interamericano, verificada jurisprudencialmente. Ellos serán expuestos en dos partes: la primera, dedicada a la revisión del Sistema Universal de Derechos Humanos (SUDH); y, la segunda, dedicada a la revisión de los sistemas de protección de derechos humanos regionales, específicamente el Sistema Interamericano de Derechos Humanos (SIDH) y el Sistema Europeo de Derechos Humanos (SEDH). Ambas partes examinaran el derecho a la identidad cultural y su titularidad por los migrantes, bajo un enfoque interpretativo de amplio espectro, con base al principio de igualdad y no discriminación; así como la focalización de este derecho de los migrantes respecto de la protección de las minorías. Al efecto se revisan los principales instrumentos internacionales erigidos en la materia, atendiendo a las observaciones generales y demás resoluciones emanadas de los órganos creados para la vigilancia del cumplimiento de estos tratados, junto a la doctrina más relevante.

Se usará una metodología dogmática y hermenéutica que será complementada con revisión bibliográfica y de jurisprudencia. En particular, las afirmaciones del estudio de las fuentes normativas serán verificadas

\footnotetext{
${ }^{4}$ CORREA, Juan José. Identidades, arraigos y soberanías. Migración peruana en Santiago de Chile. Polis Revista Latinoamericana, vol. 14, No 42, p. 167-189. 2015. p. 171.

${ }^{5}$ Sobre la noción de vulnerabilidad véase, MARIÑO Fernando, FERNÁNDEZ Carlos. Introducción y aproximación a la noción de persona y grupo vulnerable en el derecho europeo. En: FERNÁNDEZ, Liesa; MARIÑO, Fernando (coord.). La protección de las personas y grupos vulnerables en el derecho europeo. Madrid: Universidad Carlos III de Madrid, 2001. p. 19-26; MELLO, Patricia. Constitucionalismo, Transformação e Resiliência Democrática no Brasil: o Ius Constitucionale Commune na América Latina tem uma contribuição a ofrecer. Revista Brasileira Políticas Públicas, vol. 9, N², p. 254-286. 2019; MELLO, Lacerda. El derecho fundamental a la identidad cultural y el constitucionalismo en red en la jurisprudencia del Supremo Tribunal Federal de Brasil. En: FAUNDES, Juan Jorge; RAMÍREZ, Silvinba (Eds.). Derecho fundamental a la identidad cultural, abordajes plurales desde América Latina. Santiago: RIL, 2020. p. 203-238.

${ }^{6}$ BENHABIB, Seyla. The claims of culture: equality and diversity in the global era. New Yersey: Princeton university press, 2002; DE LUCAS, Javier. Europa. Derechos, Culturas. Valencia: PUV, Tirant lo Blanch, 2006.

7 ONU. Conferencia mundial contra el racismo, la discriminación racial, la xenofobia y las formas conexas de Intolerancia, documento de la Organización de Naciones Unidas A/CONF.189/PC.2/7, 2001. Disponible en: https://undocs.org/es/A/CONF.189/ PC.2/7. Acceso: 10 dic. 2020.

8 MORA CASTRO, Alberto. Inmigración, participación y estrategias de intervención en el ámbito de la salud: mediación intercultural, intervención psicosocial y promoción de derechos. En: DE LUCAS, Javier; SOLANGES Ángeles (eds.). La igualdad en los derechos: claves de la integración. España: Dykinson, 2009. p. 209-235. p. 212.
} 
con extractos de jurisprudencia internacional del Tribunal Europeo de Derechos Humanos (TEDH) y la Corte Interamericana de Derechos Humanos (Corte IDH), en base a estudio hermenéutico jurisprudencial.

\section{Derecho a la identidad cultural de los migrantes en el ámbito universal.}

El fenómeno migratorio es de naturaleza compleja: obedece a factores de diversa índole y trae aparejados múltiples consecuencias observables en distintos ámbitos. Entre ellas, tan frecuente como la migración misma, lleva aparejado el contacto entre culturas. Ello plantea la cuestión del ejercicio del DIC. Aunque no pretendemos desarrollar aquí una revisión de las discusiones extensamente formuladas desde la Antropología sobre los conceptos de identidad y cultura - pues exceden este trabajo en extensión y enfoque-, si hemos de señalar ciertos aspectos básicos necesarios para entrar en contexto respecto de las implicaciones de este derecho.

El DIC esta imbricado en las libertades inherentes a la dignidad de la persona e integra -en un proceso permanente - la diversidad cultural. Se trata de un derecho sintesis que abarca (y transversaliza) tanto derechos individuales como colectivos, requiere de la realización y efectivo ejercicio de todos los derechos humanos y, a la inversa ${ }^{9}$. Considera dos derechos enlazados: el derecho a la identidad y el derecho a la cultura ${ }^{10}$. La cultura se ha convertido en un sinónimo de identidad, un hacedor de identidades y un diferenciador ${ }^{11}$. Es una noción inherente a toda persona, que responde a interpretaciones humanas y está sujeta a una reinterpretación constante ${ }^{12}$. Los requerimientos relativos a la identidad cultural han de diversificarse dependiendo de las necesidades particulares de cada grupo, y respecto de los migrantes, el acercamiento a la cultura estará vinculado a sus sistemas de valores, sus creencias, tradiciones y empleo de su idioma. En particular, en estos casos la cohesión y cultural se suele mostrar mayor intensidad dado que resiste el desarraigo territorial.

Cuando hacemos referencia al ejercicio del DIC, hemos de entenderlo desde sus dos vertientes: como un derecho colectivo y como un derecho individual ${ }^{13}$. En el primero de los casos, este derecho se ejerce por la comunidad o esta es afectada en su conjunto ${ }^{14}$. Se trata de un derecho - de todo colectivo, grupo o minoría, caracterizado étnica y/o culturalmente, y de sus miembros- a conservar su propia cultura, su patrimonio cultural tangible o intangible, su presente y su memoria histórica; y a ser reconocidos como diferentes en sus relaciones con otros grupos de la sociedad ${ }^{15}$. Este derecho comprende el derecho a que se respeten sus

\footnotetext{
9 RUIZ CHIRIBOGA, Oswaldo. El derecho a la identidad cultural de los pueblos indígenas y las minorías nacionales: una mirada desde el sistema interamericano. Revista Internacional de Derechos Humanos, vol. 5, p. 43-69. 2006. p. 44. OLIVARES, Alberto. El Derecho a la identidad cultural. En: AGUILAR, Gonzalo (Coordinador). Nuevos derechos para una nueva Constitución. Valencia: Tirant Lo Blanch. 2019. pp, 175-190.

${ }^{10}$ FAUNDES, Juan Jorge. El derecho fundamental a la identidad cultural de los pueblos indígenas: un derecho matriz y filtro hermenéutico para las constituciones de América Latina: la justificación. Revista Brasileira de Políticas Públicas, vol. 9, Nº 2, p. 513-535. 2019b.

11 BENHABIB, Seyla. The claims of culture: equality and diversity in the global era. New Yersey: Princeton university press, 2002. p. 2.

${ }_{12}$ BENNOUNE, Karima. Informe de la Relatora Especial sobre los derechos culturales, documento de las Naciones Unidas A/ HRC/31/59, 2016. Disponible en: https://undocs.org/es/A/HRC/31/59. Acceso: 10 dic. 2020. parr. 8; RUIZ CHIRIBOGA, Oswaldo. El derecho a la identidad cultural de los pueblos indígenas y las minorías nacionales: una mirada desde el sistema interamericano. Revista Internacional de Derechos Humanos, vol. 5, p. 43-69. 2006;

13 Para mayor abundamiento respecto de estas perspectivas (individual y la colectiva) del derecho a la identidad cultural, véase DEL REAL, Alberto. El derecho a la identidad cultural: ¿derecho de la persona o derecho de los pueblos? Pamplona: Editorial Aranzadi S.A., 2014.

14 RUIZ CHIRIBOGA, Oswaldo. El derecho a la identidad cultural de los pueblos indígenas y las minorías nacionales: una mirada desde el sistema interamericano. Revista Internacional de Derechos Humanos, vol. 5, p. 43-69. 2006; DEL CARPIO, Columba. Pluralismo Jurídico, derecho humano a la identidad cultural y globalización. Navarra: Editorial Aranzadi SA, 2014.

15 FAUNDES, Juan Jorge. Derecho fundamental a la identidad cultural de los pueblos indígenas: un nuevo paradigma en la defensa penal indígena en Chile frente al Estado de Derecho hegemónico. Revista Izquierdas, No45, p. 51-78. 2019; FAUNDES, Juan Jorge. El derecho fundamental a la identidad cultural de los pueblos indígenas: un derecho matriz y filtro hermenéutico para las
} 
conocimientos, creencias, artes, moral, religión, sistema normativo, prácticas y cosmovisión, así como el derecho de sus integrantes a pertenecer a su cultura, a no ser forzado a pertenecer a una cultura diferente y o a no ser asimilado por ésta. En su dimensión individual protege al individuo y su identidad en la comunidad ${ }^{16}$.

En las últimas dos décadas, como veremos, si bien el reconocimiento del DIC ha ganado terreno en las enunciaciones de diversos instrumentos internacionales, la protección internacional del DIC no se observa contenida en un uno solo de ellos, sino que su configuración y desarrollo progresivo se desprende de la interpretación de diversos tratados, declaraciones y demás convenios internacionales, adoptados, tanto en el ámbito universal, como en el regional ${ }^{17}$. Por ello, en la revisión de estas fuentes internacionales, será necesario tomar en consideración tanto las de índole general que reconocen el DIC en concreto o bien que prohíben la discriminación, como también otras de tipo específico, que han sido adoptadas para la protección de grupos étnicos, minorías y migrantes ${ }^{18}$, encuadrados como grupos vulnerables ${ }^{19}$.

El empleo del término identidad dentro de algunos instrumentos internacionales ${ }^{20}$ hace referencia a una clara tendencia a la protección y a la promoción de la diversidad cultural en el ámbito internacional. Otros instrumentos no contienen una alusión expresa de esta categoría, pero si se emplean conceptos vinculados a la identidad cultural, tales como "cultura", "costumbres", "pluralismo cultural", "tradiciones"21. De ahí que

constituciones de América Latina: la justificación. Revista Brasileira de Políticas Públicas, vol. 9, No 2, p. 513-535. 2019a.

${ }^{16}$ DEL REAL, Alberto. El derecho a la identidad cultural: ¿derecho de la persona o derecho de los pueblos? Pamplona: Editorial Aranzadi S.A., 2014.

17 Véase el informe de la Experta independiente en la esfera de los derechos culturales, SHAHEED, Farida. Report of the independent expert in the field of cultural rights, Ms. Farida Shaheed, submitted pursuant to resolution 10/23 of the Human Rights Council, documento de las Naciones Unidas A/HRC/14/36. 2010. Disponible en: https://undocs.org/pdf?symbol=en/A/HRC/14/36. Acceso: 10 dic. 2020. Si bien el reconocimiento de la identidad cultural se observa en instrumentos que constituyen normas de hard law (tales como el PIDCP, art. 27; PIDESC; Convención para la Salvaguardia del Patrimonio Cultural Inmaterial, art. 1a), también se observa en declaraciones o normas de soft law (Declaración Universal de Derechos Humanos y otras que en menor o mayor medida hacen referencia indirecta), sin valor vinculante internacional pero de gran influencia dentro de sus respectivos sistemas. Ello no obsta para deducir que se trata de un derecho autónomo que se desarrolla como una norma emergente y cuyo ejercicio puede ser parte importante de otros derechos humanos existentes. En el ámbito Interamericano, la CADH no contempla expresamente el derecho a la identidad cultural, pero su defensa ha sido esgrimida con base en el deber de respetar integralmente los derechos de la igualdad ante la ley y el principio de no discriminación (CADH, arts. 1.1, 24, 21, 29b). La revisión del estándar fijado por la Corte IDH respecto de estas previsiones será abordado en un artículo posterior.

18 La Organización de las Naciones Unidas, a través de los órganos creados en base a su Carta (Consejo de Derechos Humanos y los comités), monitorea el cumplimiento de los principales tratados de derechos humanos. En este orden de ideas, el derecho migratorio internacional se nutre del Derecho Internacional de los derechos humanos y de la concreción que de estos efectúan los órganos de protección. Sobre esto, véase, PÉREZ-PRAT Luis. Inmigración y Derecho Internacional: ¿un acuerdo imposible? En: Curso de Derechos Humanos de Donostia-San Sebastián, vol. 7. Bilbao: Universidad del País Vasco, 2007. p. 137-164. Para entender un poco la configuración de estos órganos, empecemos señalando que en 1997 se estableció un Grupo de Trabajo Intergubernamental de Expertos en los Derechos Humanos de los Migrantes, a fin de averiguar sobre los obstáculos que se oponen a la protección plena y eficaz de los derechos humanos de los migrantes y elaborar recomendaciones para fortalecer la promoción, la protección y el ejercicio de tales derechos. Luego, en 1999 se creó la Relatoría Especial para los Derechos Humanos de los Migrantes. Por su parte, el Comité para la Protección de los Derechos de todos los Trabajadores Migratorios y de sus Familiares, que supervisa el cumplimiento de la Convención internacional sobre la protección de los derechos de todos los trabajadores migratorios y de sus familiares. También existen otros ocho comités compuestos por expertos independientes con el mandato de supervisar que los Estados parte en los tratados cumplan sus obligaciones, instrumentos jurídicos en defensa de los derechos de toda persona humana, y por ende aplicables a los migrantes. Por otra parte, la Organización Internacional del Trabajo cuenta con convenios y recomendaciones aplicables a los migrantes (véase, SHAW, Malcolm. International Law. 6a edición. Cambridge: Cambridge University Press, 2008. pp. 304-341; MURPHY, Sean. Principles of International Law. Washington: Thomson West, 2006. pp. 320-326). En el ámbito regional americano, además de los instrumentos básicos sobre derechos humanos, en 2012 se modificó el mandato, respecto de la ahora Relatoría sobre los Derechos de los Migrantes. Asimismo, en la jurisprudencia contenciosa de la Corte IDH existen casos relativos a migrantes y emisión de opiniones consultivas sobre temas específicos relacionados con estos temas.

19 Más adelante revisamos la categoría de grupos vulnerables y nuestra comprensión en relación con las minorías nacionales.

${ }^{20}$ Nos referimos por ejemplo a las disposiciones contenidas en los artículos 29 y 30 de la Convención sobre los Derechos del Niño; el artículo 31 de la Convención internacional sobre la protección de los derechos de todos los trabajadores migratorios y de sus familiares; o, el apartado b) del párrafo 2 del artículo 2 del Convenio $\mathrm{N}^{\circ} 169$ de la OIT que versa sobre el respeto de la identidad social y cultural, las costumbres y tradiciones.

21 Estas y otras nociones similares empleadas en tales instrumentos aún no están plenamente definidos y continúan en el debate de los especialistas. Sobre esto, véase RUIZ CHIRIBOGA, Oswaldo. El derecho a la identidad cultural de los pueblos indígenas y 
la existencia de derechos culturales en un sentido amplio ofrezca posibilidades para la protección del DIC ${ }^{22}$, cuya deducción procede de aquellas previsiones internacionales que promueven la cultura bajo una acepción integral e incluyente ${ }^{23}$. Dentro de aquellas que contienen previsiones relativas a la cultura, hacemos aquí un paréntesis para mencionar algunas.

Respecto de aquellas que conforman normas de hard law, observamos que en la Convención para la Salvaguardia del Patrimonio Cultural Inmaterial se promueven las representaciones, expresiones, conocimientos y habilidades que las comunidades, los grupos y, en algunos casos, las personas reconocen como parte de su patrimonio cultural. Asimismo, la Convención sobre la protección y la promoción de la diversidad de las expresiones culturales, alienta a los Estados a incorporar la cultura como elemento estratégico de las políticas nacionales e internacionales de desarrollo, así como a adoptar medidas para proteger y promover la diversidad de expresiones culturales dentro de su territorio. Otro tanto se lee en el Pacto Internacional de Derechos Sociales y Culturales (PIDESC), que reconoce el DIC como un derecho vinculado al derecho de participar en la cultura. Esta previsión tiene una amplia connotación, según lo ha definido la Relatora Especial, de suerte tal que esta participación en la cultura comprende: los derechos culturales que protegen los derechos de todas las personas, individualmente y en comunidad con otros, así como de grupos de personas, para desarrollar y expresar su humanidad, su visión del mundo y el significado que dan a su existencia y su desarrollo mediante, entre otras cosas, valores, creencias, convicciones, idiomas, los conocimientos y las artes, las instituciones y las formas de vida. También protegen el acceso al patrimonio cultural material e inmaterial como importantes recursos que permiten que esos procesos de identificación y desarrollo tengan lugar. Estos derechos abarcan una amplia gama de cuestiones, inclusive la expresión y la creación, la información y la comunicación, el idioma, la identidad y la pertenencia simultánea a comunidades múltiples, diversas y cambiantes, la búsqueda de formas específicas de vida, la educación y la capacitación, la participación en la vida cultural, y la realización de prácticas culturales ${ }^{24}$. El PIDESC en su artículo 15.1 a) también hace referencia al derecho de toda persona a participar en la vida cultural. Ello abarca no solo el derecho de los individuos a actuar en libertad, a escoger su propia identidad y a manifestar sus propias prácticas culturales, sino también el derecho a no participar en determinadas tradiciones, costumbres y prácticas, en particular aquellas que vulneran los derechos humanos y la dignidad de la persona ${ }^{25}$.

las minorías nacionales: una mirada desde el sistema interamericano. Revista Internacional de Derechos Humanos, vol. 5, p. 43-69. 2006.

22 DONDERS, Yvonne. Towards a Right to Cultural Identity? Yes, Indeed! Diritti umani y diritto internazionale, vol 12, № 5 , p. 525-548. 2018.

${ }_{23}$ Estas previsiones hacen referencia a la cultural contemplando muchos de los elementos esenciales de la identidad cultural, tales como: la participación en la vida cultural (derecho a actuar libremente y a escoger su propia identidad e identificarse o no con una o con varias comunidades), el acceso a la vida cultural (comprende, en particular, el derecho a conocer y comprender su propia cultura); y, la contribución a la vida cultural (COMITÉ DE DERECHOS ECONÓMICOS, SOCIALES Y CULTURALES. Observación general No 21: Derecho de toda persona a participar en la vida cultural (artículo 15, párrafo 1 a), del Pacto Internacional de Derechos Económicos, Sociales y Culturas, documento de las Naciones Unidas E/C.12/GC/21/Rev.1, 2009. Disponible en: https://undocs.org/es/E/C.12/GC/21. Acceso: 3 oct. 2021. parr. 9). Tales previsiones internacionales se traducen a su vez, en la obligación de los Estados parte de reconocer, respetar y proteger la cultura de las minorías como componente esencial de su propia identidad (COMITÉ DE DERECHOS ECONÓMICOS, SOCIALES Y CULTURALES. Observación general No 21: Derecho de toda persona a participar en la vida cultural (artículo 15, párrafo 1 a), del Pacto Internacional de Derechos Económicos, Sociales y Culturas, documento de las Naciones Unidas E/C.12/GC/21/Rev.1, 2009. Disponible en: https://undocs.org/es/E/C.12/ GC/21. Acceso: 3 oct. 2021. parr. 32), lo que se extiende a los migrantes, incluyendo -entre otros aspectos- su idioma, religión y folclore (COMITÉ DE DERECHOS ECONÓMICOS, SOCIALES Y CULTURALES. Observación general No 21: Derecho de toda persona a participar en la vida cultural (artículo 15, párrafo 1 a), del Pacto Internacional de Derechos Económicos, Sociales y Culturas, documento de las Naciones Unidas E/C.12/GC/21/Rev.1, 2009. Disponible en: https://undocs.org/es/E/C.12/ GC/21. Acceso: 3 oct. 2021. parr. 34).

24 SHAHEED, Farida. Informe de la Relatora Especial sobre los derechos culturales, documento de las Naciones Unidas A/67/287, 2012. Disponible en: https://undocs.org/es/A/67/287. Acceso: 3 oct. 202. parr. 5; SHAHEED, Farida, Report of the independent expert in the field of cultural rights, Ms. Farida Shaheed, submitted pursuant to resolution 10/23 of the Human Rights Council, documento de las Naciones Unidas A/HRC/14/36. 2010. Disponible en: https://undocs.org/pdf?symbol=en/A/HRC/14/36. Acceso: 10 dic. 2020. párr. 9.

25 SHAHEED, Farida. Informe de la Relatora Especial sobre los derechos culturales, documento de las Naciones Unidas A/67/287, 
Por su parte, respecto de aquellas que comprenden normas de soft law, observamos la Declaración Universal de la Unesco sobre la identidad cultural, cuyo texto contiene referencias a la cultura. En su Preámbulo le define como el conjunto de los rasgos distintivos espirituales y materiales, intelectuales y afectivos que caracterizan a una sociedad o a un grupo social y que abarca, además de las artes y las letras, los modos de vida, las maneras de vivir juntos, los sistemas de valores, las tradiciones y creencias. Otro tanto se lee en la Declaración de las Naciones Unidas sobre los derechos de los pueblos indígenas, que hace referencia a esta noción, pero no le define de manera específica. No obstante, el mecanismo de expertos ha señalado que no es necesario proceder a ello y que incluso podría ser inadecuado tratar de hacerlo, siendo lo apropiado la adopción de un enfoque de amplio espectro ${ }^{26}$.

\subsection{Identidad cultural de los migrantes con base en el principio de igualdad y no discriminación.}

Más allá del empleo taxativo de los términos alusivos a la identidad y a la cultura, el reconocimiento efectivo del DIC descansa, en primer término, sobre la protección del principio de Igualdad y no discriminación, cuya referencia se observa en numerosos instrumentos internacionales ${ }^{27}$. Este principio emana de la dignidad

2012. Disponible en: https://undocs.org/es/A/67/287. Acceso: 3 oct. 2021. parr. 25. Sobre esta previsión, el CDESC ha señalado que cuando el Pacto hace referencia a toda persona, se refiere tanto al sujeto individual como al sujeto colectivo, y por ello estos pueden ser ejercidos: individualmente; en asociación con otras; y, dentro de una comunidad o un grupo (COMITÉ DE DERECHOS ECONÓMICOS, SOCIALES Y CULTURALES. Observación general No 21: Derecho de toda persona a participar en la vida cultural (artículo 15, párrafo 1 a), del Pacto Internacional de Derechos Económicos, Sociales y Culturas, documento de las Naciones Unidas E/C.12/GC/21/Rev.1, 2009. Disponible en: https://undocs.org/es/E/C.12/GC/21. Acceso: 3 oct. 2021 . parr. 9.). De ello se colige una clara referencia al ejercicio de la identidad cultural en sus dos vertientes: de forma individual o colectiva. 26 MECANISMO DE EXPERTOS SOBRE LOS DERECHOS DE LOS PUEBLOS INDÍGENAS. Estudio sobre el papel de los idiomas y la cultura en la promoción y protección de los derechos y la identidad de los pueblos indígenas, documento de las Naciones Unidas A/HRC/EMRIP/2012/3. 2012. Disponible en: https://undocs.org/es/A/HRC/EMRIP/2012/3. Acceso: 10 dic. 2020 .

27 Algunos de estos instrumentos internacionales en el ámbito universal e interamericano son: Carta de la OEA (artículo 3.1); Convención Americana sobre Derechos Humanos (artículos 1 y 24); Declaración Americana de los Derechos y Deberes del Hombre (artículo 2); Protocolo Adicional a la Convención Americana sobre Derechos Humanos en Materia de Derechos Económicos, Sociales y Culturales, "Protocolo de San Salvador" (artículo 3); Carta de las Naciones Unidas (artículo 1.3); Declaración Universal de Derechos Humanos (artículos 2 y 7); Pacto Internacional de Derechos Económicos, Sociales y Culturales (artículos 2.2 y 3 ); Pacto Internacional de Derechos Civiles y Políticos (artículos 2 y 26); Convención Internacional sobre la Eliminación de todas las Formas de Discriminación Racial (artículo 2); Convención sobre los Derechos del Niño (artículo 2); Declaración de los Derechos del Niño (Principio 1); Convención Internacional sobre la Protección de los Derechos de Todos los Trabajadores Migratorios y de sus Familiares (artículos 1, 7, 18.1, 25, 27, 28, 43, 45.1, 48, 55 y 70); Convención sobre la Eliminación de Todas las Formas de Discriminación contra la Mujer (artículos 2, 3, 5 a 16); Declaración sobre la Eliminación de Todas las Formas de Intolerancia y Discriminación Fundadas en la Religión o las Convicciones (artículos 2 y 4); Declaración de la Organización Internacional del Trabajo (OIT) relativa a los Principios y Derechos Fundamentales en el Trabajo y su Seguimiento (2.d); Convenio No. 97 de la Organización Internacional del Trabajo (OIT) sobre los Trabajadores Migrantes (revisado) (artículo 6); Convenio No. 111 de la Organización Internacional del Trabajo (OIT) relativo a la Discriminación en Materia de Empleo y Ocupación (artículos 1 a 3); Convenio No. 143 de la Organización Internacional del Trabajo (OIT) sobre los Trabajadores Migrantes (disposiciones complementarias) (artículos 8 y 10); Convenio No. 168 de la Organización Internacional del Trabajo (OIT) sobre el Fomento del Empleo y la Protección contra el Desempleo (artículo 6); Declaración y Programa de Acción de Viena, Conferencia Mundial de Derechos Humanos, 14 a 25 de junio de 1993 (I.15; I.19; I.27; I.30; II.B.1, artículos 19 a 24; II.B.2, artículos 25 a 27); Declaración sobre los Derechos de las Personas Pertenecientes a Minorías Nacionales o Étnicas, Religiosas y Lingüísticas (artículos 2, 3, 4.1 y 5); Conferencia Mundial contra el Racismo, la Discriminación Racial, la Xenofobia y las Formas Conexas de Intolerancia, Programa de Acción, (párrafos de la Declaración: 1, 2, 7, 9, 10, 16, 25, 38, 47, 48, 51, 66 y 104); Convención Relativa a la Lucha contra las Discriminaciones en la Esfera de la Enseñanza (artículo 3); Declaración sobre la Raza y los Prejuicios Raciales (artículos 1, 2, 3, 4, 5, 6, 7, 8 y 9); Declaración sobre los Derechos Humanos de los Individuos que no son Nacionales de País en que Viven (artículo 5.1.b y 5.1.c); entre otros. 
personal ${ }^{28}$, elemento presente en el Derecho Internacional de los derechos humanos ${ }^{29}$. La dignidad humana - entendida como una cualidad intrínseca, irrenunciable e inalienable de todo y a cualquier ser humano independientemente de su condición de nacional o extranjero-, exige el respeto de su legítima esfera de autonomía e independencia ${ }^{30}$. Esta noción se traduce en un concepto normativo fundamental a partir del cual los derechos humanos pueden ser deducidos ${ }^{31}$, incluyendo el derecho a la identidad cultural.

En el sentido anterior, se ha sugerido una nueva conceptualización del principio de igualdad para hacerle más efectivo. Ramírez plantea su conceptualización como emancipación, al concebirlo como una carta de navegación que permite que el sistema internacional de derechos humanos -conformado por el conjunto de derechos identificados y definidos como prioritarios- determine el modo de su aplicación y su prelación frente a sujetos específicos. Bajo esta nueva óptica se propone alcanzar una simetría entre las culturas contrastantes, colocarlas en una misma situación de prelación y generar los mecanismos necesarios para que esta igualdad se traduzca en respeto a los derechos, al marco institucional, y a la vez se construyan espacios de interacción y de diálogo intercultural ${ }^{32}$.

Una muestra de los planteamientos planteados se observa en el artículo $1^{\circ}$ de la Declaración Universal de los Derechos Humanos de 1948 (DUDH) ${ }^{33}$. En su Preámbulo este instrumento reivindica la libertad, la justicia y la paz en el mundo con base en el reconocimiento de la dignidad intrínseca y de los derechos iguales e inalienables de todos los miembros de la familia humana. El catálogo de derechos humanos reconocidos en este instrumento es de índole variada y aplicable completamente a los migrantes en su calidad de personas. En este orden de ideas, su artículo 27 reconoce el derecho de toda persona a tomar parte libremente en la vida cultural de su comunidad ${ }^{34}$ por tratarse de un componente esencial de la propia identidad ${ }^{35}$. Estamos en presencia de previsiones amplias respecto de los sujetos a los que se les reconocen los derechos humanos junto a referencias asociadas a su participación respecto de los derechos culturales con base en su dignidad intrínseca.

\footnotetext{
${ }^{28}$ La dignidad es una cualidad que se predica de toda persona, con independencia de cuál sea su comportamiento. En cuanto cualidad ínsita de todo ser humano y exclusiva del mismo, se traduce primordialmente en la capacidad de decidir libre y racionalmente cualquier modelo de conducta, con la consecuente exigencia de respeto por parte de los demás y aparece indisolublemente ligada al concepto de derechos humanos (MARÍN, Ma Luisa. La dignidad humana, los Derechos Humanos y los Derechos Constitucionales. Revista de Bioética y Derecho, N 9, p.1-8. 2007. p. 2; VALLS, Ramón. El concepto de dignidad humana. Revista de Bioética y Derecho, N 5, p. 278-285. 2015. p. 283-285). También v. SARMENTO, Daniel. Dignidade da pessoa humana conteúdo, trajetórias e metodologia. Belo Horizonte: Fórum, 2016; BARROSO, Luis Roberto. La dignidad de la persona humana em el derecho constitucional contemporáneo. La construcción de un concepto jurídico a la luz de la jurisprudencia mundial. Traducción Simone Nevares. Bogotá: Universidad del Externado de Colombia, 2014.

29 GROSS ESPIELL, Héctor. La dignidad humana en los instrumentos internacionales sobre los derechos humanos. Anuario de Derechos Humanos, vol. 7, Nº 1, p. 193-224. 2003. p. 197.

${ }_{30}$ HÛBNER, Jorge. Panorama de los derechos humanos. Santiago: Editorial Andrés Bello. 1973. p. 19.

31 HABERMAS, Jürgen. El concepto de dignidad humana y la utopía realista de los derechos humanos. Diánoia, vol. LV, p. 3-25. 2010

32 Véase, RAMÍREZ, Silvina. Igualdad como Emancipación: los Derechos Fundamentales de los Pueblos indígenas. En: MARCELO ALEGRE, Marcelo; GARGARELLA, Roberto (coordinadores). El Derecho a la Igualdad, aportes para un Constitucionalismo Igualitario. Buenos Aires: Abeledo-Perrot, 2012. p. 30-50. p. 44.

33 Fuerza acotar que esta declaración se erige como un estandarte internacional de índole universal a seguir en materia de protección de los derechos humanos, formulando principios generales que precisan el sentido de los derechos y libertades fundamentales. 34 Aunque la DUDH no goza de carácter vinculante, lo cierto es que se reserva afirmar el carácter imperativo de los principios que la integran, e insta a todos a que se guíen por ellos, lo que resulta de vital importancia para la realización de los propósitos de las Naciones Unidas. Véase, REMIRO BROTÓNS, Antonio. Derecho Internacional Público: Tomo I. Principios fundamentales. Madrid: Tecnos, 1987. p. 69. En igual sentido, GRIGORY IVANOVITCH, Tunkin. Droit international public: problèmes thèoriques. Paris: Editions A. Pedone, 1965. p. 100; GONZALES CAMPOS, Julio, SÁNCHEZ RODRÍGUEZ, Luis Ignacio y SÁENZ DE SANTA MARÍA, Paz Andrés. Curso de derecho internacional público. Madrid: Civitas, 2002. p. 113.

35 COMITÉ DE DERECHOS ECONÓMICOS, SOCIALES Y CULTURALES. Observación general No 21: Derecho de toda persona a participar en la vida cultural (artículo 15, párrafo 1 a), del Pacto Internacional de Derechos Económicos, Sociales y Culturas, documento de las Naciones Unidas E/C.12/GC/21/Rev.1, 2009. Disponible en: https://undocs.org/es/E/C.12/GC/21. Acceso: 3 oct. 2021.
} 
Tal amplitud también se observa en el artículo 5 de la Declaración Universal de la Unesco sobre la identidad cultural del año $2001^{36}$. No obstante, el reconocimiento de este derecho respecto de los migrantes se lee de un modo más explícito en el artículo 5 letra f) de la Declaración sobre los derechos bumanos de los individuos que no son nacionales del país en que viven, adoptada por la Asamblea General en su resolución 40/144 en 1985. En este instrumento internacional también se reconoce - en favor de los individuos que no son nacionales del país en que viven - el derecho a conservar su propio idioma, cultura y tradiciones: claras referencias al ejercicio del DIC por parte de los migrantes. En consecuencia, respecto de estos grupos, el acercamiento a la cultura estará estrechamente relacionado con el ejercicio de sus libertades inherentes a su dignidad personal, integrando así la diversidad cultural.

En relación con los planteamientos que anteceden, hemos de destacar las previsiones del artículo 27 y 2.1 del Pacto Internacional de Derechos Civiles y Políticos (PIDCP), en las que se estipula la obligación de los Estados de brindar un trato no discriminatorio respecto de los migrantes que se encuentren bajo su jurisdicción ${ }^{37}$, lo que -bajo una óptica de amplio espectro- sería aplicable respecto del DIC de estos. Por su parte, el PIDESC - en su artículo 15.1 literal a - también hace referencia al derecho de toda persona a participar en la vida cultural, incluyendo a los migrantes con base al principio de igualdad y no discriminación. Otro tanto lo leemos en el artículo 31 de la Convención Internacional sobre la Protección de los Derechos de todos los Trabajadores Migratorios y de sus familiares respecto del resguardo del DIC de los migrantes en contextos laborales, requiriendo igualdad de trato y mismas condiciones entre estos y los nacionales. La aplicación de las previsiones contenidas en este último instrumento se extiende a los familiares de los trabajadores migrantes ${ }^{38}$.

En el ámbito universal el instrumento de tipo específico más resaltante que ha sido adoptado específicamente para combatir la discriminación es la Convención Internacional sobre la Eliminación de todas las formas de Discriminación Racial de 1965 (CIEDR) ${ }^{39}$. En su artículo $1^{\circ}$ se define la discriminación racial ${ }^{40}$, partiendo de la noción de igualdad derivada directamente de la unidad del género humano e inseparable de la dignidad esencial de la persona. Este instrumento plantea la incompatibilidad de toda actuación discriminatoria que por considerar superior a un determinado grupo- conduzca a tratarlo con privilegio; o que, a la inversa -por considerarlo inferior- lo trate discriminatoriamente en cuanto al goce de sus derechos ${ }^{41}$. Ello adquiere un

\footnotetext{
36 En este instrumento se extiende a toda persona el derecho de poder participar en la vida cultural que elija y ejercer sus propias prácticas culturales en su art. 5

37 COMITÉ DE DERECHOS HUMANOS. Observación General No. 31: Naturaleza de la obligación jurídica general impuesta a los Estados Parte en el Pacto, documento de las Naciones Unidas CCPR/C/21/Rev.1/Add.13, 2004. Disponible en http://www. refworld.org/cgi-bin/texis/vtx/rwmain/opendocpdf. pdf?reldoc=y\&docid=478b26ea2. Acceso: 8 sep. 2021. párr. 10-11; CORTE IDH. Resolución 2/11 sobre la Situación de los Detenidos de la Bahía de Guantánamo, Estados Unidos, Medidas Cautelares 259-02, 2002. disponible en https://www.cidh.oas.org/pdf\%20files/Resoluci\%C3\%B3n\%20 2-11\%20Guant\%C3\%A1namo.pdf. Acceso: 5 abr. 2021.

38 COMITÉ DE PROTECCIÓN DE LOS DERECHOS DE TODOS LOS TRABAJADORES MIGRATORIOS Y DE SUS FAMILIARES. Observación general N 2 sobre los derechos de los trabajadores migratorios en situación irregular y de sus familiares, documento de las Naciones Unidas CMW/C/GC/2, 2013. Disponible en: https://www.mre.gov.py/SimorePlus/Adjuntos/ Informes/CMW\%20N\%C2\%BA\%202.pdf. Acceso: 1 oct. 2020. Junto a la protección de la identidad cultural se incluye el reconocimiento de otros derechos culturales a los trabajadores migrantes y sus familiares, a través de diversas previsiones: el artículo 43, párrafo $1 \mathrm{~g}$ ) y el artículo 45, párrafo $1 \mathrm{~d}$ ), sobre el acceso a la vida cultural y la participación en ella.

39 Este instrumento fue inspirado en la Declaración sobre la Eliminación de todas las Formas de Discriminación Racial de 1963. Esta última, si bien constituyó un gran avance y antecedente hacia la prohibición de las conductas antidiscriminatorias, debido a su naturaleza no vinculatoria en el ámbito de las Naciones Unidas no comportó la obligatoriedad suficiente para transformarse en un instrumento que garantizara los derechos a la igualdad (FERRER, Luis Gabriel. La Convención Internacional sobre la Eliminación de Todas las Formas de Discriminación Racial (FASCÍCULO 5). En: COMISIÓN NACIONAL DE LOS DERECHOS HUMANOS (editores). Colección del Sistema Universal de protección de los Derechos Humanos. México: Comisión Nacional de los Derechos Humanos, 2012, p. 1 - 88. p. 20, 62)

${ }^{40}$ La Convención Internacional sobre Eliminación de todas las formas de Discriminación racial define a la discriminación como: [...] toda distinción, exclusión, restricción o preferencia basada en motivos de raza, color, linaje u origen nacional o étnico que tenga por objeto o por resultado anular o menoscabar el reconocimiento, goce o ejercicio en condiciones de igualdad, de los derechos humanos y libertades fundamentales en las esferas política, económica, social, cultural o en cualquier otra esfera de la vida pública. ${ }^{41}$ COMISIÓN INTERAMERICANA DE DERECHOS HUMANOS. Informe sobre Terrorismo y Derechos Humanos, documento de la Organización de los Estados Americanos OEA/Ser.L/V/11.116, 2002. Disponible en: http://www.acnur.org/filead-
} 
significado relevante para los migrantes, por constituir - en la mayoría de los casos- grupos minoritarios dentro de las sociedades de acogida. No obstante, se ha señalado que esta promoción de antidiscriminación de alguna forma se diluye al permitir ciertas distinciones, exclusiones, restricciones y preferencias entre ciudadanos y no ciudadanos ${ }^{42}$. Por ello el Comité para la Eliminación de la Discriminación Racial -órgano que supervisa la aplicación del CIEDR por parte de los Estados que la han suscrito ${ }^{43}$ - (CERD), en un intento por remover esta ambigüedad ha sostenido que este instrumento hace referencia a una prohibición básica de discriminación ${ }^{44}$ - por vía legislativa, política o práctica- entre diferentes grupos de no nacionales con base a la raza, color, ascendencia u origen étnico. En consecuencia, la diferencia de trato basada en la ciudadanía o en la condición de migrante constituye discriminación si los criterios para establecer esa diferencia -en atención a los objetivos y propósitos de la CIEDR - no se aplican para alcanzar un objetivo legítimo y no son proporcionales al logro de este ${ }^{45}$.

Junto a las previsiones anteriores, también conviene acotar que el principio de Igualdad y no discriminación se encuentra prescrito en varios instrumentos internacionales como un elemento necesario para el resguardo de otros derechos, entre los que se incluye el DIC. En este sentido, el ejercicio de este derecho ha sido asociado a la realización de otros derechos fundamentales: A) integridad personal y un trato humano acorde a la dignidad de los inmigrantes y sus familiares privados de libertad ${ }^{46}$; B) Derecho a la enseñanza de la lengua y cultura maternas en la educación de los hijos de los trabajadores migrantes en situación regular e irregular ${ }^{47}$; C) Protección de las tierras, territorios y recursos, así como aquellos territorios tradicionales

$\mathrm{min} /$ scripts/doc.php?file=fileadmin/Documentos/BDL/2002/1975, Acceso: 10 mar. 2021. p. 24; PALACIOS TREVIÑO, Jorge. Los derechos humanos de los trabajadores migratorios y sus familias. En: OEA (editor). Universalismo y Regionalismo a Inicios del Siglo XXI. Río de Janeiro: OEA, 2010. p. 427-452. p. 441.

${ }^{42}$ GHOSH, Bimal. Derechos humanos y migración: el eslabón perdido. MORÁN QUIROZ, Luis (trad.). México: Red Internacional de Migración y Desarrollo Zacatecas, 2008. p. 40.

43 Este órgano de expertos independientes recibe los informes periódicos de los Estados sobre cómo se están aplicando los derechos. Los Estados deben presentar un informe inicial un año después de su adhesión a la Convención y, posteriormente, cada dos años. Para más información, véase sitio web oficial de Naciones Unidas. Comité para la Eliminación de la Discriminación Racial. Disponible en: https://www.ohchr.org/sp/hrbodies/cerd/pages/cerdindex.aspx. Acceso: 11 abr. 2021.

${ }^{44}$ COMITÉ PARA LA ELIMINACIÓN DE LA DISCRIMINACIÓN RACIAL. Recomendación General No 30 relativa a la discriminación contra los no ciudadanos, 2004. Disponible en: https://www.refworld.org.es/docid/5d7fc 37 ca.html. Acceso: 30 may. 2021. párr. 4.

45 COMITÉ PARA LA ELIMINACIÓN DE LA DISCRIMINACIÓN RACIAL. Recomendación General No 30 relativa a la discriminación contra los no ciudadanos, 2004. Disponible en: https://www.refworld.org.es/docid/5d7fc37ca.html. Acceso: 30 mayo 2021. párr. 4. párr. 4. Adicionalmente, el CERD contempla deberes de acciones positivas para los Estados, pues estos no solo están obligados a abstenerse de cometer actos que pudieran ser violatorios del principio de no discriminación, sino que también debe adoptar las medidas necesarias para garantizar tal principio mediante mecanismos de cumplimiento -algunos de naturaleza administrativa (Exclusivamente para los Estados se aplica la presentación de informes, el procedimiento de alerta temprana y el examen de denuncias entre los Estados; mientras que los que permiten la participación de los propios afectados está relacionado con el examen de denuncia de particulares; y el último, que es de naturaleza judicial e interestatal, implica como requisitos estrictos, por ejemplo, el acceso a la Corte Internacional de Justicia) - de ciertos requisitos estrictos ( FERRER, Luis Gabriel. La Convención Internacional sobre la Eliminación de Todas las Formas de Discriminación Racial (FASCÍCULO 5). En: COMISIÓN NACIONAL DE LOS DERECHOS HUMANOS (editores). Colección del Sistema Universal de protección de los Derechos Humanos. México: Comisión Nacional de los Derechos Humanos, 2012, p. 1- 88. p. 36). Por su parte, el Comité de Derechos Humanos de las Naciones Unidas ha sostenido que las medidas restrictivas deben ajustarse al principio de proporcionalidad; deben ser adecuadas para desempeñar su función protectora; debe ser el instrumento menos perturbador de los que permitan conseguir el resultado deseado, y deben guardar proporción con el interés que debe protegerse. "El principio de proporcionalidad debe respetarse no solo en la ley que defina las restricciones sino también por las autoridades administrativas y judiciales que la apliquen. Los Estados deben garantizar que todo procedimiento... explique las razones de la aplicación de medidas restrictivas" (COMITÉ DE DERECHOS HUMANOS. Observación General No. 15, Comentarios generales adoptados por el Comité de los Derechos Humanos, la situación de los extranjeros con arreglo al Pacto, documento de las Naciones Unidas HRI/GEN/1/Rev.7, 1986. Disponible en: http://hrlibrary.umn.edu/hrcommittee/Sgencom15.html. Acceso: 3 nov. 2020. parr. 14, 15).

${ }^{46}$ COMITÉ DE PROTECCIÓN DE LOS DERECHOS DE TODOS LOS TRABAJADORES MIGRATORIOS Y DE SUS FAMILIARES. Observación general $\mathrm{N}^{\circ} 2$ sobre los derechos de los trabajadores migratorios en situación irregular y de sus familiares, documento de las Naciones unidas CMW/C/GC/2, 2013. Disponible en: https://undocs.org/es/CMW/C/GC/2. Acceso: 4 oct. 2020. parr. 15.

47 MECANISMO DE EXPERTOS SOBRE LOS DERECHOS DE LOS PUEBLOS INDÍGENAS. Estudio sobre el papel de los idiomas y la cultura en la promoción y protección de los derechos y la identidad de los pueblos indígenas, documento de las 
donde se encuentran sus hogares y sus familias y demás espacios en los que practican sus culturas y aseguramiento de las conexiones de los pueblos indígenas con estos territorios tradicionales ${ }^{48}$, incluso para aquellos que han migrado por razones de trabajo o estudio ${ }^{49}$; D) Derecho a la salud de los inmigrantes, mediante políticas que promuevan estos servicios tomando en cuenta consideraciones culturales y de género y que favorezcan una reducción de los obstáculos lingüísticos, de comunicación y culturales ${ }^{50}$.

De acuerdo con la revisión descrita en los párrafos que anteceden, observamos que las bases en las que se funda la prohibición de discriminación difieren de uno a otro instrumento; pero en todas se repiten las referencias respecto de la raza, el color, el lenguaje, la religión, el origen nacional, el origen social, lugar de nacimiento y sobre todos ellos se hace referencia constante a la identidad y la cultural.

Asimismo, la interpretación de distintos órganos de supervisión de los instrumentos en referencia informan la aplicación del principio de igualdad y no discriminación respecto de los migrantes como imperativo del derecho internacional general, en cuanto es aplicable a todo Estado. Ello implica que el Estado no puede actuar ignorando la aplicación de este principio en perjuicio de un determinado grupo de personas ${ }^{51}$, incluyendo los migrantes.

Conforme a lo planteado, una interpretación amplia de los diversos instrumentos internacionales antes revisados nos permite observar la reiterada presencia de prohibiciones de discriminación arbitraria en relación con el trato que se brinda a los migrantes en lo tocante al ejercicio de sus derechos y libertades fundamentales. Ello se traduce en el deber de reconocimiento por parte de los Estados de las diferencias y particularidades de los migrantes como un elemento de su dignidad personal. Por tanto, estos últimos estarían autorizados a justificar el ejercicio del DIC con base al principio de igualdad y no discriminación.

\subsection{Identidad cultural de los migrantes y su catalogación como minorías.}

Sin perjuicio del reconocimiento, en general, del DIC para todas las personas -incluyendo a los migrantes- con base al principio de igualdad y no discriminación, en segundo término, revisaremos su reconocimiento, en particular, respecto de aquellas personas pertenecientes a minorías.

El reconocimiento del DIC en relación con la protección de las personas pertenecientes a minorías se contiene en el artículo 27 del PIDCP que contempla eldeber de los Estados en que existan minorías de permitir que los miembros de estas ejerzan su identidad cultural. Ello también se colige del artículo 2 del referido pacto, según el cual la aplicación del artículo 27 se extiende a todos los individuos que se encuentren

Naciones Unidas A/HRC/EMRIP/2012/3. 2012. Disponible en: https://undocs.org/es/A/HRC/EMRIP/2012/3. Acceso: 10 dic. 2020. parr. 78 .

48 Sobre el derecho a la identidad cultural de los pueblos indígenas véase, FAUNDES, Juan Jorge. El derecho fundamental a la identidad cultural de los pueblos indígenas: un derecho, matriz y filtro hermenéutico para las constituciones de América Latina: la justificación. Revista Brasileira de Políticas Públicas, vol. 9, № 2, p. 513-535. 2019b; FAUNDES, Juan Jorge. El derecho fundamental a la identidad cultural de los pueblos indígenas, configuración conforme el derecho internacional y perspectivas de su recepción en Chile. Revista Ius et Praxis, vol. 26, No 1, p. 77-100. 2020a; FAUNDES, Juan Jorge; RAMÍREZ, Silvina (Eds.). Derecho fundamental a la identidad cultural, abordajes plurales desde América Latina. Santiago: RIL, 2020. Faundes, Juan Jorge, Buen Día, Paloma. "Hermenéuticas del derecho humano a la identidad cultural en la jurisprudencia interamericana, un análisis comparado a la luz del ICCAL”. Revista Brasileira de Políticas Públicas. ISSSN 2179-8338, Vol. 12, N².

49 MECANISMO DE EXPERTOS SOBRE LOS DERECHOS DE LOS PUEBLOS INDÍGENAS. Estudio sobre el papel de los idiomas y la cultura en la promoción y protección de los derechos y la identidad de los pueblos indígenas, documento de las Naciones Unidas A/HRC/EMRIP/2012/3. 2012. Disponible en: https://undocs.org/es/A/HRC/EMRIP/2012/3. Acceso: 10 dic. 2020. parr. 24 .

50 BUSTAMANTE, Jorge. Informe del Relator Especial sobre los derechos humanos de los migrantes, documento de las Naciones Unidas A/HRC/14/30, 2010. Disponible en: https://undocs.org/es/A/HRC/14/30. Acceso: 4 oct. 2020.

51 CORTE IDH. Opinión Consultiva OC-18/03 sobre Condición Jurídica y Derechos de los Migrantes Indocumentados (2003), 17 septiembre 2003, Serie A No 18. 
en su territorio y estén sujetos a su jurisdicción ${ }^{52}$. Se trata de un derecho autónomo, que se suma a los demás derechos de que pueden disfrutar esas personas en virtud del Pacto ${ }^{53}$.

Otro tanto se lee en la Declaración de la Organización de Naciones Unidas (ONU) sobre los derechos de las personas pertenecientes a minorias nacionales o étnicas, religiosas y lingüisticas, adoptada en 1992. Este instrumento internacional constituye el primer antecedente en el ámbito universal dedicado exclusivamente al reconocimiento de los derechos de las minorías, estableciendo un vínculo entre el resguardo de sus derechos y el desarrollo de la sociedad en su conjunto dentro de un marco democrático basado en el estado de derecho ${ }^{54}$. En el artículo 1 de este instrumento se regulan previsiones a favor de las minorías sobre la base de su identidad nacional o étnica, cultural, religiosa y lingüística y se dispone el deber de los Estados de proteger su existencia.

Una referencia más explícita respecto de la protección del DIC de las personas pertenecientes a minorías - en este caso, minorías étnicas - la encontramos en el Convenio $\mathrm{N}^{\circ} 169$ de la OIT ${ }^{55}$. En este instrumento se plantean dos postulados básicos: el derecho de los pueblos indígenas a mantener y fortalecer sus culturas, formas de vida e instituciones propias; $y$, su derecho a participar de manera efectiva en las decisiones que les afectan. Las disposiciones iniciales de este convenio precisan que los sujetos a los que se les reconoce el DIC son los pertenecientes a los pueblos indígenas y tribales. Además, el artículo 35 del Convenio 169 de la OIT acuerda la aplicación hermenéutica de otros instrumentos internacionales relativos a la protección de la identidad cultural de los grupos indígenas, junto a las recomendaciones de los relatores de Naciones Unidas, conformando un estándar internacional para la protección de los derechos humanos de los pueblos indígenas vinculante desde la ratificación del Convenio $169^{56}$.

No obstante, bajo una interpretación amplia del referido convenio y en base al principio de igualdad y no discriminación, en tales disposiciones también se incluye a los migrantes que, aunque se encuentren fuera de sus territorios de origen, pertenezcan a estas minorías étnicas ${ }^{57}$. Al efecto, la calidad de trabajador

\footnotetext{
${ }_{52}$ COMITÉ DE DERECHOS HUMANOS. Observación general No 23: Derecho de las minorías (artículo 27), documento de las naciones unidas HRI/GEN/1/Rev.9 (Vol. I), 1994. Disponible en: https://undocs.org/es/HRI/GEN/1/Rev.9(Vol.I). Acceso: 30 jul. 2021. parr. 5.1 y 5.2 .

53 COMITÉ DE DERECHOS HUMANOS. Observación general No 23: Derecho de las minorías (artículo 27), documento de las naciones unidas HRI/GEN/1/Rev.9 (Vol.I), 1994. Disponible en: https://undocs.org/es/HRI/GEN/1/Rev.9(Vol.I). Acceso: 30 jul. 2021.

${ }^{54}$ GUDMUNDUR, Alfredsson; TURK, Danilo. International mechanisms for the monitoring and protection of minority rights: Their advantages, disadvantages and interrelationships. En: BLOED, Arie (ed.). Monitoring human rights in Europe: comparing international procedures and mechanisms. Kluwer: Norwell MA, 1993. p. 169-86. p. 172.

55 Otras organizaciones internacionales, como la Organización Internacional del Trabajo (OIT), también han elaborado normas sobre la protección de los derechos culturales y el ejercicio de la identidad cultural. Esta vez nos referiremos a la protección internacional de estos derechos respecto de los pueblos indígenas y tribales. Con anterioridad, la OIT había adoptado en 1957, un primer instrumento internacional vinculante, conocido como el Convenio núm. 107 sobre Poblaciones indígenas y tribales en países independientes. Posteriormente, en junio de 1989, la Conferencia Internacional del Trabajo de la OIT adoptó en forma tripartita con participación de los gobiernos, organizaciones de empleadores y de trabajadores este Convenio $\mathrm{N}^{\circ} 169$. Es oportuno acotar que, en el proceso de revisión de este convenio efectuado para el periodo de 1987 a 1989, se tomó en consideración la participación y consulta de varios pueblos indígenas y tribales. En las previsiones de este instrumento se plantean dos postulados básicos: el derecho de los pueblos indígenas a mantener y fortalecer sus culturas, formas de vida e instituciones propias; y, su derecho a participar de manera efectiva en las decisiones que les afectan. De modo tal que, de sus previsiones se desprende la protección del derecho a la identidad cultural.

${ }^{56}$ FAUNDES, Juan Jorge. El derecho fundamental a la identidad cultural de los pueblos indígenas: un derecho, matriz y filtro hermenéutico para las constituciones de América Latina: la justificación. Revista Brasileira de Políticas Públicas, vol. 9, № 2, p. 513-535. 2019b; FAUNDES, Juan Jorge. El derecho fundamental a la identidad cultural de los pueblos indígenas, configuración conforme el derecho internacional y perspectivas de su recepción en Chile. Revista Ius et Praxis, vol. 26, N 1, p. 77-100. 2020a; FAUNDES, Juan Jorge. Horizontes Constituyentes. Reconocimiento de los pueblos indígenas en América Latina: Los casos de Chile y Bolivia. Curitiba: Editora Appris, 2020b; FAUNDES, Juan Jorge; RAMÍREZ, Silvina (Eds.). Derecho fundamental a la identidad cultural, abordajes plurales desde América Latina. Santiago: RIL, 2020.

${ }^{57}$ Lo anterior se desprende de su artículo 1 letra a), que establece solo 2 condicionantes que deben reunir los sujetos a los que se les aplican las previsiones de este convenio: a) que sus condiciones sociales, culturales y económicas les distingan de otros sectores de la colectividad nacional; b) que estén regidos total o parcialmente por sus propias costumbres o tradiciones o por una legislación especial. Así también lo ha entendido el consejo de Derechos Humanos al interpretar las previsiones del artículo 30 del convenio 169 de la OIT, sosteniendo que estas disposiciones no solo aplican a los miembros de pueblos indígenas que ostentan la nacionalidad
} 
intermitente, estacional, temporal o migrante ha sido una de las características más destacables de los integrantes de los pueblos originarios, por lo que, el establecimiento de las anteriores normas internacionales no se originó, en un comienzo, en razón a su condición étnica sino por su condición de trabajadores bajo tales modalidades, como parte importante de la naturaleza de dichos individuos ${ }^{58}$. De hecho, gran parte de la migración indígena se realiza dentro de los territorios fronterizos contemplados en el artículo 32 del convenio $169^{59}$. Estos grupos de migrantes indígenas pueden enfrentar una multiplicidad de retos adicionales a los que enfrenta cualquier migrante por aspirar a conservar sus identidades culturales ${ }^{60}$. En consecuencia, este instrumento, en la materia, se dirige a asegurar la protección del DIC respecto de aquellos migrantes étnicos que se encuentren fuera de sus territorios de origen.

Hasta aquí hemos referido a las principales fuentes en que se fundamenta el DIC y a las dos perspectivas de su configuración, general en torno a la prohibición de discriminación y particular como derecho de las personas pertenecientes a minorías. Pero una debida formulación del derecho supone también una correcta identificación de sus titulares. En consecuencia, nos preguntamos, para estos efectos, cómo comprendemos las categorías "minorías" y "grupos vulnerables" contenidas y usadas, indistintamente, en los instrumentos internacionales justificantes del DIC y por la doctrina incumbente.

En primer lugar, el significado de una u otra noción puede ser equivalente o no según el contexto normativo o el enfoque del DIC que defina. En segundo término, en relación a las lecturas de los sistemas regionales de derechos humanos, hemos de tener presente que los respetivos tribunales europeo e interamericano de derechos humanos, han tomado decisiones, principalmente, en relación a grupos humanos diversos y en contextos bien diferentes: "minorías nacionales" en Europa y "pueblos indígenas" en América. No obstante, como veremos a la luz de las propias fuentes, esta titularidad del DIC se reconoce sobre la base de (i) una identidad cultural compartida y (ii) la autodefinición de los grupos, como elementos materiales en común reconocidos a "minorías nacionales" (especialmente en el caso europeo) y "pueblos indígenas" (en particular en el caso interamericano $)^{61}$. Así, el tratamiento específico del respectivo grupo depende, en gran medida, de cada sistema regional de derechos humanos, incluso del orden nacional y de los instrumentos internacionales con los que se vincula cada estado y que circunscriben, en definitiva, el respectivo marco jurídico aplicable y los titulares del DIC en cada contexto. En este sentido, para Toniatti, incluso es posible usar el concepto de "grupos" y "minorías nacionales" (de mayor consideración y comprensión en Europa), para fines de comparación analítica de los derechos asociados a la diversidad cultural ${ }^{62}$.

del país de destino, sino que también es aplicable a aquellas personas indígenas no nacionales de un país (OIM. respuestas presentadas por la Organización Internacional para la Migraciones (OIM) a algunas de las preguntas realizadas por la honorable Corte Interamericana de Derechos Humanos, durante la audiencia realizada en el marco de la solicitud de opinión Consultiva sobre niñez migrante los días 9 y 10 de octubre de 2013, documento de la OIM DR/CDH/091, 2013. Disponible en: https://www.corteidh. or.cr/sitios/Observaciones/complementarias/escrito-OIM-14-11-2013.pdf. Acceso: 4 sep. 2021. parr. 29). Lo anterior también se lee explícitamente en el artículo 20.3 a) del Convenio 169 de la OIT, en el que se regula el deber del Estado de brindar igual protección en las condiciones de trabajo con arreglo a la legislación laboral del territorio en el que estos migrantes indígenas se encuentren. ${ }^{58}$ GROS ESPIELL, Héctor. La Organización Internacional del Trabajo y los derechos humanos en América Latina. México: UNAM, 1978. p. 13.

59 OIM. respuestas presentadas por la Organización Internacional para la Migraciones (OIM) a algunas de las preguntas realizadas por la honorable Corte Interamericana de Derechos Humanos, durante la audiencia realizada en el marco de la solicitud de opinión Consultiva sobre niñez migrante los días 9 y 10 de octubre de 2013, documento de la OIM DR/CDH/091, 2013. Disponible en: https://www.corteidh.or.cr/sitios/Observaciones/complementarias/escrito-OIM-14-11-2013.pdf. Acceso: 4 sep. 2021. parr. 26.

60 BLACKWELL Maylei; HERNÁNDEZ, Rosalva; HERRERA, Juan; MACLEOD, Morna; RAMÍREZ, Renya; SIEDER, Rachel; SIERRA, María; SPEED, Shannon. Cruces de fronteras, identidades indígenas, género y justicia en las Américas. Desacatos, $\mathrm{N}^{\circ}$ 31, p. 13-34, sep./dic. 2009. p. 22.

${ }_{61}$ AGUILAR, Gonzalo. La dinámica internacional de la cuestión indígena. Santiago: Librotecnia. 2007. p. 315.

62 TONIATTI, Roberto. El paradigma constitucional de la inclusión de la Diversidad cultural: notas para una comparación Entre los modelos de protección de las minorías Nacionales en europa y de los pueblos indígenas en Latino américa. 2015 Disponible en: http://www.jupls.eu/images/JPs_WP_RT_Ponencia_2015.pdf. Acceso: 3 oct. 2021. 
Paralelamente y sin que signifique una oposición conceptual, como veremos, se utiliza un enfoque centrado en la "vulnerabilidad", conforme el cul, para Mariño las "minorías" o "grupos minoritarios", también son grupos vulnerables ${ }^{63}$.

Entre los intentos de definir lo que debe entenderse por minorías, Capotori, entonces Relator Especial de la Subcomisión de Prevención de Discriminaciones y Protección a las Minorías, ha sostenido que una minoría es:

"Un grupo numéricamente inferior al resto de la población de un Estado, que se encuentra en una posición no dominante y cuyos miembros, que son nacionales del Estado, poseen características étnicas, religiosas o lingüísticas diferentes de las del resto de la población y manifiestan, aunque sólo sea implícitamente, un sentimiento de solidaridad para preservar su cultura, sus tradiciones, su religión o su idioma" (la traducción es nuestra) ${ }^{64}$.

Otra definición sostenida por Deschenes le contempla como

"grupo de ciudadanos de un Estado, dotados de características étnicas, religiosas o lingǘsticas diferentes a las de la mayoría de la población, solidarios los unos de los otros, animados, aunque sea implícitamente, de una voluntad colectiva de supervivencia y que tienden a la igualdad de hecho y de derecho con la mayoría" (la traducción es nuestra) ${ }^{65}$.

Observamos que entre sus componentes se hace referencia al elemento de la nacionalidad, lo que podría constituir un criterio diferenciador capaz de privar a ciertas personas o grupos del goce de los derechos previstos en los anteriores instrumentos ${ }^{66}$. Nos resulta más destacable el requisito relativo a la posición no dominante ${ }^{67}$ del grupo en cuestión, particularidad que se observa respecto de los grupos migratorios en las sociedades de acogida. Esto es relevante especialmente en la práctica, al observarse características comunes entre los migrantes y las minorías -nacionales, étnicas, lingüísticas y religiosas- que generalmente se encuentran en una posición no dominante respecto de la sociedad en que viven y sus culturas, idiomas o creencias religiosas pueden ser diferentes de los de la mayoría.

Por ello, para los efectos de esta investigación -siempre haciendo reserva del alcance dado en las respectivas fuentes-, siguiendo a María José Andrade, entendemos que: (i) no existe una definición convencional internacional única, aceptada universal o regionalmente, sobre "minorías nacionales"8"; (ii) no obstante, siguiendo la doctrina mayoritaria, es posible definir "minoría nacional" como:

“... un grupo no dominante y numéricamente inferior al resto de la población de un Estado en el que están asentados desde hace mucho tiempo, integrado por personas que comparten una identidad cultural distinta de la mayoritaria -etnia, religión, tradiciones o costumbres-, la cual pretenden preservar". ${ }^{69}$

\footnotetext{
${ }^{63}$ MARIÑO, Fernando; FERNÁNDEZ Carlos. Introducción y aproximación a la noción de persona y grupo vulnerable en el derecho europeo. En: FERNÁNDEZ, Liesa; MARIÑO, Fernando (coord.). La protección de las personas y grupos vulnerables en el derecho europeo. Madrid: Universidad Carlos III de Madrid, 2001. p. 24.

${ }^{64}$ CAPOTORI, Francesco. Study on the rights of persons belonging to ethnic, religious and linguistic minorities, documento de las Naciones Unidas E/CN.4/Sub.2/384/Rev.1, 1979. Disponible en: https://digitallibrary.un.org/record/10387?ln=en. Acceso: 15 may. 2021. parr. 568.

65 DESCHENES, Jules. Proposal concerning a definition of the term "minority", documento de las Naciones unidas E/CN.4/ Sub.2/1985/31, 1985. Disponible en: https://digitallibrary.un.org/record/88267?ln=en. Acceso: 7 agosto 2021. párr. 181.

${ }_{66}$ GRUPO DE TRABAJO SOBRE LAS MINORIAS. Comentario del grupo de trabajo sobre las minorías acerca de la declaración sobre los derechos de las personas pertenecientes a minorías nacionales o étnicas, religiosas y lingüísticas, documento de las Naciones Unidas E/CN.4/Sub.2/AC.5/2005/2, 2005. Disponible en: file:///C:/Users/56931/Downloads/E_CN.4_Sub.2_ AC.5_2005_2-ES.pdf. Acceso: 11 jul. 2021. parr. 6).

${ }^{67}$ Frase utilizada por Francesco Capotori en su propuesta de definición elaborada en 1979. Véase, CAPOTORI, Francesco. Study on the rights of persons belonging to ethnic, religious and linguistic minorities, documento de las Naciones Unidas E/CN.4/ Sub.2/384/Rev.1, 1979. Disponible en: https://digitallibrary.un.org/record/10387?ln=en. Acceso: 15 may. 2021. parr. 568.

68 SORIANO DÍAZ, Ramón Luis. Los Derechos de las Minorías. Madrid: Editorial Mad, 1999. p.18; RUIZ, Eduardo. Minorías Europeas y Estado de Derecho. En: GARCÍA RODRÍGUEZ, Isabel (ed.). Las Minorías en una Sociedad Democrática y Pluricultural. Madrid; Universidad de Alcalá, 2001. p. 51-90. p. 59.

69 ANDRADE, María José. Pueblos indígenas y minorías nacionales: similitudes y diferencias en la protección internacional de sus derechos. Revista Campos en Ciencias Sociales, Nº, v. 2, pp. 13-48. p. 15-16: ARP, Jörn, Las minorías nacionales y su protec-
} 
Paralelamente, como anticipamos, la noción de minoría se asocia también a la vulnerabilidad. En este marco, la vulnerabilidad, para es comprendida como la falta o desequilibrio de poder y subrepresentación por parte de grupos específicos ${ }^{70}$. En el sentido indicado, entenderemos por "grupo vulnerable" (concepto de frecuente uso doctrinal) a las colectividades de individuos que: (i) participan de formas de vida usualmente diversas al patrón social y/o cultural dominante y, como resultado de ello, son estigmatizados socialmente; (ii) tienen un status en desventaja para el ejercicio de sus derechos, en general de facto, pero a veces jurídico, respecto a los demás ciudadanos, siendo objeto de prácticas discriminatorias (explícitas o implícitas); (iii) presentan dificultades para que sus demandas sean consideradas por medio de la representación política (en los poderes legislativo y ejecutivo); (iv) como consecuencia de los factores precedentes, demandan acciones de protección específicas para su defensa y o para reducir las brechas relativas a su igualdad jurídica y especialmente material ${ }^{71}$. Desde este enfoque material, efectivamente, "grupos vulnerables" y "minorías nacionales", por una parte, comparten factores comunes (como la situación de desventaja social y política frente a los sectores mayoritarios); y, por otra, la identidad cultural es un elemento base de las minorías nacionales que puede estar presente o no en los grupos vulnerables según el grupo en particular de que se trate.

Con base en los anteriores planteamientos, la vulnerabilidad constituye un elemento que caracteriza a los migrantes y permite considerarles como minorías, por estar sujetos a una situación de desventaja e "impotencia" política, social e incluso jurídica, determinadapor la estructura de poder de un país. Estas estructuras de poder, relativas a las posiciones de poder que en toda sociedad tienen unos respecto de otros, también hacen referencia a una estructura cultural, comprendida por un conjunto de elementos de tipo despectivo que tienden a justificar las diferencias entre nacionales y no nacionales ${ }^{72}$. Así, la vulnerabilidad de los migrantes refiere al conjunto de características no idiosincráticas que generan debilidad, desventaja o problemas para su desempeño y movilidad social y que actúan como frenos u obstáculos para la adaptación de los actores a los cambiantes escenarios sociales ${ }^{73}$. Ella está determinada por la “...carencia relativa o absoluta de recursos simbólicos, sociales, emocionales o materiales, o por la dificultad o imposibilidad de su uso en un determinado contexto histórico, debido a constricciones institucionales, políticas, económicas, sociales o culturales. La falta efectiva de estos recursos es lo que hace a ciertos tipos de migrantes más vulnerables que a otros" ${ }^{\text {"4 }}$ , lo que se incrementa con la discriminación, la estigmatización y el rechazo social.

Conforme lo planteado, podemos sintetizar que los migrantes son grupos en que: (i) la identidad cultural es un elemento de cohesión colectiva; (ii) muchas veces son, efectivamente, grupos de población minoritaria, pero no siempre, como en algunos países latinoamericanos; y no obstante, (iii) sí se caracterizan por su desventaja social y política.

Finalmente, aunque no existe un consenso respecto de lo que debe entenderse por minoría y o la tipología de estas es bastante extensa ${ }^{75}$, ello no obsta para incluir dentro de ellas a los migrantes como minorías, por cumplir con la mayoría de los criterios relevantes para clasificar a un grupo dentro de las nociones más

ción en Europa. Madrid: Centro de Estudios Políticos y Constitucionales, 2008. p. 405. CAPOTORI, Francesco. Study on the rights of persons belonging to ethnic, religious and linguistic minorities, documento de las Naciones Unidas E/CN.4/Sub.2/384/Rev.1, 1979. Disponible en: https://digitallibrary.un.org/record/10387?ln=en. Acceso: 15 may. 2021. párr. 568.

70 BUSTAMANTE, Jorge. Un marco de referencia acerca de la vulnerabilidad de los migrantes como sujetos de los derechos humanos. Taller sobre mejores prácticas en materia de migración. CEPAL, 2000.

71 FAUNDES, Juan Jorge, MELLO, Patricia Perrone Campos. “Grupos vulnerables”, en PIZZI, Jovino, CENSI, Maximiliano (Coordinadores), Glosario de Patologías Sociales. Pelotas: Observatório Global de Patologias Sociais, Universidad Federal de Pelotas (UFPel). 2021 Tb. v. Mariño, 2001, p. 21-23.

72 BUSTAMANTE, Jorge. Un marco de referencia acerca de la vulnerabilidad de los migrantes como sujetos de los derechos humanos. Taller sobre mejores prácticas en materia de migración. CEPAL, 2000.

73 RODRÍGUEZ VIGNOLI, Jorge. Vulnerabilidad y grupos vulnerables: un marco de referencia conceptual mirando a los jóvenes, 2001. Disponible en: https://www.cepal.org/sites/default/files/publication/files/7150/S018659_es.pdf. Acceso: 18 sep. 2021.

74 AYSA-LASTRA, Maria; CACHÓN, Lorenzo. Introduction: Vulnerability and Resilience of Latin American Immigrants During the Great Recession. En: AYSA-LASTRA, Maria; CACHÓN, Lorenzo (eds.). Immigrant vulnerability and resilience: Comparative perspectives on Latin American immigrants during the Great Recession. España: Springer. 2015. p. 1-21. p. 11.

75 TONIATTI, Roberto. Los derechos del pluralismo cultural en la Nueva Europa. R.V.A.P., No. 58, vol. 2, p. 17-48. 2000. 
aceptadas al respecto. En consecuencia, estas minorías tienen derecho a que se les reconozcan sus particularidades y diferencias mediante el pleno ejercicio del DIC. . Al respecto, se ha sostenido que la Declaración sobre los derechos de las personas pertenecientes a minorías nacionales o étnicas, religiosas y lingüísticas hace referencia a cuatro categorías diferentes, cuyos derechos tienen un contenido y una importancia hasta cierto punto diferentes en base a las necesidades de estos grupos ${ }^{76}$. No obstante, consideramos que junto a estas categorías debiesen incluirse las minorías transnacionales - constituidas por migrantes, exiliados y desplazados- también denominadas nuevas minorías. Medda-Windischer se refiere a los inmigrantes bajo esta denominación, sosteniendo que la protección de su identidad sería una de las bases de un verdadero proceso de integración. En estos procesos los referidos grupos pueden desarrollar un genuino sentido de lealtad y pertenencia común con el resto de la población sin estar amenazados de ser asimilados, lo que ocasionaría resistencia y alienación ${ }^{77}$. Desde la ONU también se ha referido a estos grupos bajo similares términos, por ser minorías visibles de origen inmigrante que padecen discriminación $\operatorname{directa}^{78}$. Estas posiciones coinciden con las previsiones del artículo 27 del PIDCP dirigidas a todo tipo de minorías, sean grandes o pequeñas, recientes o históricas, territorialmente dispersas o concentradas. Ello hace referencia a un derecho cultural universal que puede ser reclamado por cualquier individuo y que le acompaña dondequiera que vaya ${ }^{79}$.

En consecuencia, este derecho puede ser reclamado por los migrantes como nuevas minorías y bajo las razones antes expuestas. Entonces, el reconocimiento del derecho a ejercer la identidad cultural (a sostener individual y colectivamente sus modos de vida, valores culturales, cosmovisión, religiosidad, etc.)para el caso de los migrantes, bajo una interpretación estricta de los instrumentos internacionales, subyace en la base de su estatus internacional de integrantes de minorías. Los Estados que han suscrito y ratificado estos instrumentos internacionales tienen el deber de asegurar la realización y el ejercicio del DIC en el cumplimiento desus obligaciones internacionales adoptadas en la materia ${ }^{80}$.

\footnotetext{
${ }^{76}$ Así, las personas pertenecientes a grupos definidos exclusivamente como minoría religiosa gozan solamente de los derechos especiales relacionados con la profesión y la práctica de su religión. Respecto de las personas pertenecientes a grupos definidos exclusivamente como minorías lingüísticas, estos disponen solo de los derechos especiales relacionados con el aprendizaje y el uso de su propio idioma. Quienes perteneciesen a grupos definidos como minorías étnicas tendrían unos derechos más amplios relacionados con la preservación y el desarrollo de otros aspectos de su cultura, puesto que la pertenencia étnica se define en general por una amplia concepción de la cultura, de la que forma parte un modo de vida. La categoría de minoría nacional tendría entonces unos derechos todavía más sólidos, no solo en relación con su cultura, sino también con la preservación y desarrollo de su identidad nacional (GRUPO DE TRABAJO SOBRE LAS MINORIAS. Comentario del grupo de trabajo sobre las minorías acerca de la declaración sobre los derechos de las personas pertenecientes a minorías nacionales o étnicas, religiosas y lingüísticas, documento de las Naciones Unidas E/CN.4/Sub.2/AC.5/2005/2, 2005. Disponible en: file:///C:/Users/56931/Downloads/E_CN.4_Sub.2_ AC.5_2005_2-ES.pdf. Acceso: 11 jul. 2021.parr. 6.)

77 MEDDA-WINDISCHER, Roberta. Fundamentos para la protección de las antiguas y nuevas minorías. En: RUIZ, Eduardo; URRUTIA, Gorka (eds.). Gestión de la diversidad en sociedades tradicionalmente divididas: Derechos humanos en contextos multiculturales. ¿Acomodo de derechos o derechos de acomodo? Bilbao: Instituto de Derechos Humanos, 2010. p. 67-98. p. 75. $\mathrm{Al}$ respecto se ha señalado que la protección de las minorías tiene por objeto velar por que tal integración no se convierta en una asimilación no deseada o socave la identidad colectiva de las personas que viven en el territorio del Estado (GRUPO DE TRABAJO SOBRE LAS MINORIAS. Comentario del grupo de trabajo sobre las minorías acerca de la declaración sobre los derechos de las personas pertenecientes a minorías nacionales o étnicas, religiosas y lingüísticas, documento de las Naciones Unidas E/CN.4/ Sub.2/AC.5/2005/2, 2005. Disponible en: file:///C:/Users/56931/Downloads/E_CN.4_Sub.2_AC.5_2005_2-ES.pdf. Acceso: 11 jul. 2021. parr. 6. párr. 27 y 28).

78 Tanto el Relator sobre discriminación como la Experta Independiente sobre minorías, ambos de Naciones Unidas, se han pronunciado respecto de los inmigrantes como grupos constituyentes de minorías, al referirse a las prácticas históricas de discriminación en el trato a los migrantes irregulares y en el ejercicio de sus derechos. Entre otros, véase DIÈNE, Doudou; MCDOUGALL, Gay. Promoción y protección de todos los derechos humanos, civiles, políticos, económicos, sociales y culturales, incluido el derecho al desarrollo/racismo, discriminación racial, xenofobia y formas conexas de intolerancia: seguimiento y aplicación de la declaración y programa de acción de Durban, documento de las Naciones Unidas A/HRC/7/19/Add.5 y A/HRC/7/23/Add.3 (Informe conjunto), 2008. Disponible en: https://undocs.org/sp/A/HRC/7/19/Add.5. Acceso: 12 abril 2021. resumen.

${ }_{79}$ KYMLICKA, Will. La evolución de las normas europeas sobre los derechos de las minorías: los derechos a la cultura, la participación y la autonomía. Revista Española de Ciencia Política, N 17, p. 11-50, oct. 2007. P 19.

${ }_{80}$ Algunos autores sostienen que el Estado no estaría obligado a proteger y promover la identidad cultural de todos los grupos que se encuentran en su territorio ya que estos voluntariamente han renunciado a su cultura al salir de sus territorios y que por lo tanto este deber solo subyace respecto de los grupos etno-culturales (RUIZ CHIROBOGA, Oswaldo El derecho a la identidad cultural de los pueblos indígenas y las minorías nacionales: una mirada desde el sistema interamericano. Revista Internacional de Derechos
} 
Por otra parte, si bien se ha sostenido que las previsiones del artículo 27 del PIDCP solo hacen referencia a derechos negativos de no-interferencia - en lugar de derechos positivos ${ }^{81}$, el referido artículo implica una obligación hacia el Estado de asegurar la realización y el ejercicio de este derecho, junto a su amparo contra toda negativa o violación ${ }^{82}$. Las peticiones o reclamos que plantean las diferentes minorías respecto del DIC varían según sus necesidades y experiencias particulares ${ }^{83}$. No obstante, estas se incardinan en la necesidad de los migrantes de conservar aquellos símbolos, narraciones, costumbres, lenguas e historias que formen parte del modo como se perciben a sí mismos como personas y su sentido de pertenencia a determinadas culturas. En consecuencia, la promoción y la protección de los derechos de las minorías exige que los Estados presten particular atención tales a cuestiones.

\section{Derecho a la Identidad Cultural de los migrantes en el ámbito regional.}

Las fuentes principales y las auxiliares concurrentes existentes en el ámbito universal -y reseñadas en el aparte anterior-, deben ser articuladas con los respectivos tratados de los sistemas regionales de derechos humanos, en particular la Convención Americana de Derechos Humanos (CADH), el Convenio Europeo de Derechos Humanos $\mathrm{CEDH})^{84}$, y otros instrumentos regionales y o especializados como revisaremos a continuación.

Humanos, $\mathrm{N}^{\circ}$ 5, año 3, p. 43-69. 2006; KYMLICKA, Will. La evolución de las normas europeas sobre los derechos de las minorías: los derechos a la cultura, la participación y la autonomía. Revista Española de Ciencia Política, N 17, p. 11-50, oct. 2007. Estos autores asocian el ejercicio de la identidad cultural a los objetivos de autonomía -entre otros- que persiguen estos grupos y por lo tanto, respecto de los migrantes lo que debe buscarse para ellos es una integración más justa. Sin embargo, este tipo de distinciones no hace más que exacerbar sus diferencias y conceder mayores beneficios para unos (grupos étnicos nacionales), respecto de los migrantes, e ignora aquellos casos en los que estos últimos salen de sus territorios por razones forzadas. Por ello, sostenemos -como expondremos más adelante- que en virtud de lo contemplado en el artículo 27 del PIDCP en conjunto con otros instrumentos aplicables, que el DIC debe ser reconocido para los migrantes que se encuentren dentro del territorio del Estado en cuestión.

${ }^{81}$ KYMLICKA, Will. La evolución de las normas europeas sobre los derechos de las minorías: los derechos a la cultura, la participación y la autonomía. Revista Española de Ciencia Política, No 17, p. 11-50, oct. 2007. p. 18.

82 COMITÉ DE DERECHOS HUMANOS. Observación general 21: Trato humano de las personas privadas de libertad (artículo 10), documento de las Naciones Unidas HRI/GEN/1/Rev.9, 1992. Disponible en: https://conf-dts1.unog.ch/1\%20SPA/Tradutek/Derechos_hum_Base/CCPR/00_2_obs_grales_Cte\%20DerHum\%20\%5BCCPR\%5D.html\#GEN21. Acceso: 2 ene. 2021. parr. 6.1

${ }_{83}$ Por ejemplo, no puede considerarse como un derecho universal el reclamo de algunas minorías respecto del derecho a gobernarse a sí mismas, reclamo que aplica solamente a aquellas con un tipo concreto de historia y territorio KYMLICKA, Will. La evolución de las normas europeas sobre los derechos de las minorías: los derechos a la cultura, la participación y la autonomía. Revista Española de Ciencia Política, $N^{\circ} 17$, p. 11-50, oct. 2007. p. 19). En el caso de los pueblos indígenas se plantea la necesidad de conservar su integridad cultural, lo que significa la continuación de una gama de patrones culturales, incluidos los patrones que establecen derechos a la tierra y recursos, y están incorporados en el derecho consuetudinario indígena y las instituciones que regulan las sociedades indígenas (ANAYA, James. International human rights and indigenous peoples: the move toward the multicultural state. Arizona Journal of International \& Comparative Law, vol. 21, $N^{\circ} 1$ pp. 13-61. 2004.). Por su parte, respecto de los migrantes los reclamos obedecerán a otras necesidades propias de estos grupos, como facilidades para su reconocimiento como residentes dentro de las sociedades de acogida KYMLICKA, Will. La evolución de las normas europeas sobre los derechos de las minorías: los derechos a la cultura, la participación y la autonomía. Revista Española de Ciencia Política, N 17, p. 11-50, Oct. 2007; y la obtención de protección específica contra la discriminación y el racismo por emplear su propio lenguaje, ejercitar sus prácticas tradicionales y creencias religiosas. Los migrantes forjan y sostienen relaciones sociales de múltiples cruces con las que ligan sus sociedades de origen y asentamiento" y por ello, en muchos casos su principal interés se centra en mantener tales relaciones con los miembros de sus comunidades de origen, según BASCH, Nina; GLICK SCHILLER, Linda; SZANTON BLANC, Cristina. Nations Unbound: Transnational Project, Postcolonial Predicaments, and De-territorialized Nation States. New York: Routledge, 1993. p. 7). En el caso de los migrantes indígenas, los procesos de migración no sólo transforman las prácticas y costumbres tradicionales, sino que permiten recuperar las identidades indígenas, tanto al atravesar una frontera como al entrar en los espacios urbanos del país de origen. Por ello, en el caso de estos migrantes sus aspiraciones no se limitan en conservar relaciones sociales sino también prácticas y entendimientos culturales, HERNÁNDEZ, Rosalva; HERRERA, Juan; MACLEOD, Morna; RAMÍREZ, Renya; SIEDER, Rachel; SIERRA, María; SPEED, Shannon. Cruces de fronteras, identidades indígenas, género y justicia en las Américas. Desacatos, $N^{\circ} 31$, p. 13-34, septiembre/diciembre. 2009. p. 29).

${ }_{84}$ En la literatura en español se le refiere, indistintamente a "El Convenio Europeo de Derechos Humanos" o "La Convención Europea de Derechos Humanos". No obstante, el sitio oficial del CEDH traduce su nombre desde el inglés ("European Convention 


\subsection{Identidad cultural de los migrantes con base en el principio de igualdad y no discriminación.}

Iniciamos esta sección acotando en líneas generales que, si bien es cierto que en los instrumentos base de ambos sistemas internacionales de derechos humanos (la CADH en el SIDH y el CEDH en el SEDH) no se reconoce textualmente el DIC ${ }^{85}$, su aplicación se deriva de otras fuentesregionales de interés, junto con los instrumentos universales anteriormente reseñados. Así, en el SIDH la fundamentación sustantiva del derecho humano a la identidad cultural ha estado relacionada con una interpretación también amplia y compleja del derecho a la igualdad y la no discriminación contenida en la CADH en su artículo 24: "Igualdad ante la Ley. Todas las personas son iguales ante la ley. En consecuencia, tienen derecho, sin discriminación, a igual protección de la ley" ${ }^{86}$. Por su parte, en el SEDH la aplicación del artículo 14 del CEDH relativo al derecho a un trato equitativo ${ }^{87}$ también se vincula con el derecho humano a la identidad cultural. De hecho, sobre el derecho a un trato equitativo se ha sostenido que “...el propósito del Convenio es imponer a los Estados una obligación positiva de asegurar que los derechos fundamentales estén garantizados sin discriminación" ${ }^{88}$. Nótese que en ambos marcosse desprende el reconocimiento del DIC para todas las personas -incluyendo a los migrantes- con base al principio de igualdad y no discriminación. Una revisión más detallada respecto de cada sistema de derechos humanos nos permitirá confirmar los anteriores planteamientos.

En el caso del SIDH, son relevantes tanto la Carta de la OE $A$ como instrumento base regional y el Protocolo Adicional de la Convención Americana sobre Derechos Humanos en materia de Derechos Económicos, Sociales y Culturales o Protocolo de San Salvador. Estos instrumentos aseguran los derechos económicos sociales y culturales -interconectados- con el DIC y otros derechos. Dice el Protocolo de San Salvador en su Preámbulo:

“[...] con arreglo a la Declaración Universal de los Derechos Humanos y a la Convención Americana sobre Derechos Humanos, sólo puede realizarse el ideal del ser humano libre, exento del temor y de la miseria, si se crean condiciones que permitan a cada persona gozar de sus derechos económicos, sociales y culturales, tanto como de sus derechos civiles y políticos; [...] si bien los derechos económicos, sociales y culturales fundamentales han sido reconocidos en anteriores instrumentos internacionales, tanto de ámbito universal como regional, resulta de gran importancia que éstos sean reafirmados, desarrollados, perfeccionados y protegidos en función de consolidar en América, sobre la base del respeto integral a los derechos de la persona, el régimen democrático representativo de gobierno así como el derecho de sus pueblos al desarrollo, a la libre determinación y a disponer libremente de sus riquezas y recursos naturales".

Adicionalmente el artículo 14.1.a) de este instrumento señala que:

"Los Estados partes en el presente Protocolo reconocen el derecho de toda persona a: participar en

on Human Rights"), como "Convenio Europeo de Derechos Humanos", por lo que nosotros seguiremos esta última nomenclatura (incluyendo nuestras traducciones del inglés), salvo en los casos de citas literales que refieren a "la Convención". v. https://www. echr.coe.int/documents/convention_spa.pdf .

${ }^{85}$ Como verificaremos más adelante, ha sido la Corte IDH la que ha establecido que la Convención Americana ampara el derecho fundamental a la identidad cultural de los pueblos indígenas, pero también de otros grupos minoritarios tradicionales y sus respectivos integrantes.

86 Sobre este asunto también se observa el planteamiento del Juez Abreu, quien ha sostenido que los artículos 24 y 1.1 de la CADH que establecen, respectivamente, la igualdad ante la ley y la obligación de respetar los derechos, "son dos ejes transversales que cruzan" el conjunto de derechos dado que los miembros de estos grupos minoritarios culturales “....son libres e iguales a todas las personas en dignidad y derechos y deberán gozar plenamente de los derechos humanos y las libertades fundamentales, sin obstáculos y discriminación de ninguna índole [incluso] en algunos casos, los Estados deberán adoptar medidas positivas para garantizar el pleno ejercicio de todos sus derechos humanos" (CORTE IDH, Caso Comunidad Indígena Yakye Axa Vs. Paraguay. Fondo, Reparaciones y Costas. Sentencia de 17 de junio de 2005. Voto parcialmente disidente Juez Abreu, párr. 34).

87 De hecho, La Comisión Europea de Derechos Humanos ha observado en relación con este derecho a un trato equitativo que “...la CEDH no garantiza derechos a las minorías. Los derechos y libertades consagrados en la Convención son, según al artículo 1 de la Convención, garantizados a 'todos' dentro de la jurisdicción de una Alta Parte Contratante. El disfrute de los derechos y libertades consagrados en la Convención se garantizará, de conformidad con el artículo 14, sin discriminación en ningún aspecto, como, entre otros, la asociación con una minoría nacional" (la negrita es nuestra). Véase, Comisión EDH, G. and E. v. Norway ("Hhe Alta Case”), N 9278/81 y 9415/81, admisibilidad, decisión 3 octubre de 1983, p. 35.

88 TEDH, Case Buckley v. United Kindom, N²0348/92, sentencia 29 septiembre de 1996. Voto disidente, Juez Petiti. p. 27. 
la vida cultural y artística de la comunidad”. Otro tanto añade el artículo 14.2 al sostener que “... los Estados partes en el presente Protocolo deberán adoptar las medidas necesarias para asegurar el pleno ejercicio de este derecho" $"$.

Concordamos con el Juez Abreu, quien sostiene que, si bien en el campo del Derecho Internacional de los Derechos Humanos "el DIC aún está en permanente construcción y depende primordialmente de los derechos culturales", el artículo 14 del Protocolo de San Salvador es una fuente de este derecho. En consecuencia, cuando señala que los estados reconocen el derecho de toda persona a participar en la vida cultural de la comunidad, establece la obligación específica de los estados de adoptar las medidas necesarias para asegurar el pleno ejercicio del $\mathrm{DIC}^{90}$. De esta forma, este derecho es considerado integrante del derecho a participar en la vida cultura ${ }^{1}$. Desde esta perspectiva, por una parte, tiene el carácter de un derecho económico social y cultural. Sin embargo, por otra, el mismo Protocolo de San Salvador se preocupa de señalar su estatus jurídico equivalente a los derechos civiles y políticos, y de destacar la obligación de cumplimiento efectivo del derecho $^{92}$. En este orden de ideas, hemos de tomar en consideración - dentro del marco del SIDH- la Declaración Americana de los Derechos y Deberes del Hombre de 1948 (DADH). Esta declaración, más allá de su naturaleza jurídica no vinculante (fuente auxiliar), bajo la hermenéutica de la Corte IDH constituye un instrumento básico vinculado a la Carta de la OE $A$ y la CADH. En este sentido, la DADH ha sido especialmente relevante para la Corte IDH en los casos referentes a países que solo han ratificado la Carta de la OEA y no la CADH. Su artículo XIII dispone que: "Toda persona tiene el derecho de participar en la vida cultural de la comunidad...", categoría que naturalmente incluye a los migrantes a quienes se les reconoce - en consecuencia- el derecho el DIC por ser un derecho que integra o forma parte del derecho a participar en la vida cultural ${ }^{93}$.

En el ámbito europeo, observamos similares referencias respecto del derecho a participar de la vida cultural, lo que constituye -por su puesto- una referencia velada respecto del DIC de todas las personas. Aquí hemos de referirnos al Convenio Marco del Consejo de Europa sobre el valor del patrimonio cultural para la sociedad de 2005 (Convenio Faro) ${ }^{94}$, cuyo Preámbulo reza:

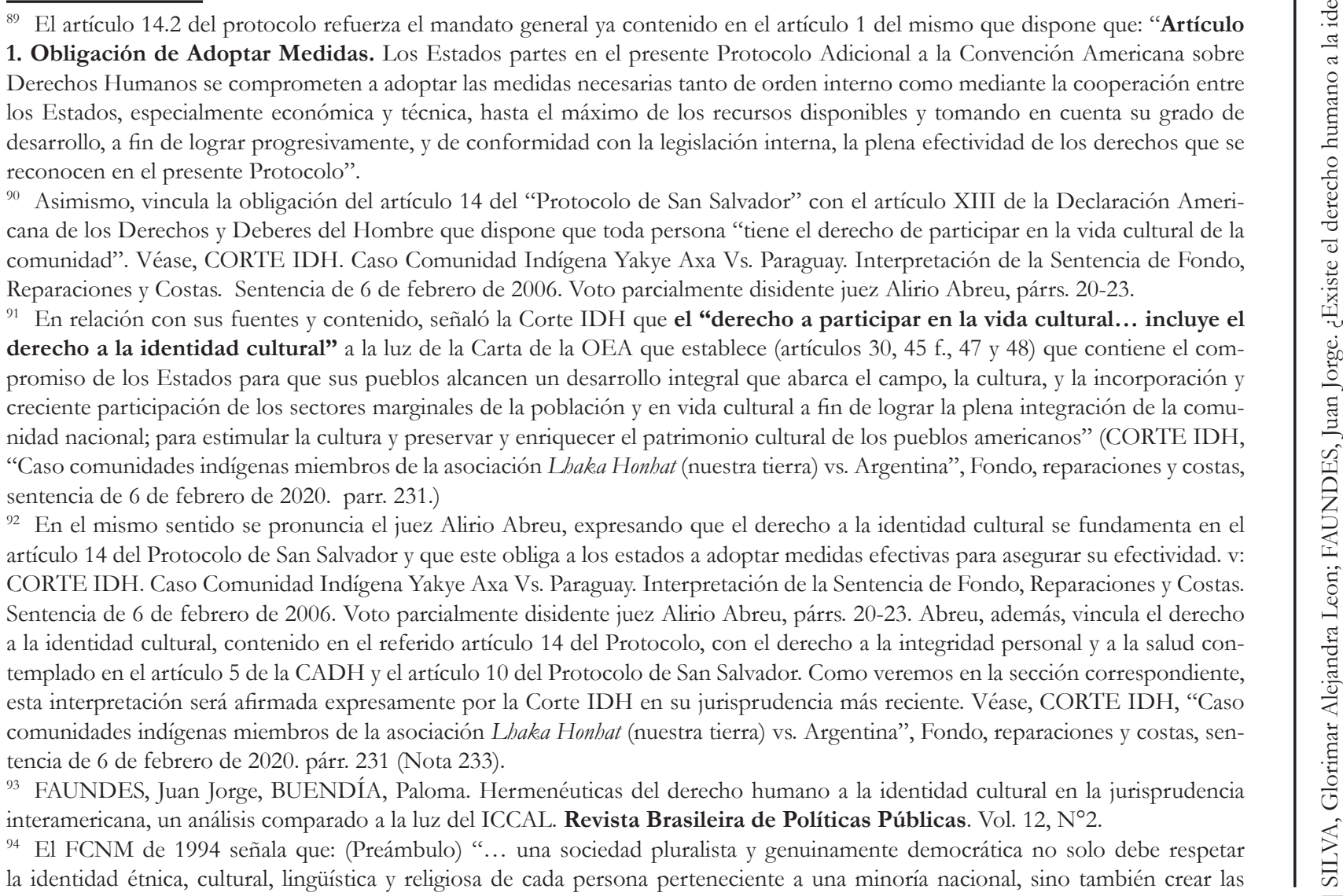


“... uno de los objetivos del Consejo de Europa es lograr... que la persona y los valores humanos ocupen un lugar central dentro de un concepto más amplio e interdisciplinar de patrimonio cultural; [...] toda persona tiene derecho a establecer vínculos con el patrimonio cultural de su elección... lo que constituye un aspecto de su derecho a tomar parte libremente en la vida cultural, consagrado en la Declaración Universal de Derechos Humanos de las Naciones Unidas (1948) y garantizado por el Pacto Internacional de Derechos Económicos, Sociales y Culturales (1966)" (la negrita es nuestra).

Adicionalmente, en su artículo 1 se definen los objetivos del Convenio Faro de 2005:

“ Los Estados parte del presente Convenio acuerdan: reconocer que los derechos referentes al patrimonio cultural son inherentes al derecho a tomar parte en la vida cultural, consagrado en la Declaración Universal de Derechos Humanos; reconocer la responsabilidad personal y colectiva respecto al patrimonio cultural; subrayar que el objetivo de la conservación del patrimonio cultural y de su uso sostenible es el desarrollo de las personas y la calidad de vida; adoptar las medidas necesarias para llevar a la práctica... la aportación del patrimonio cultural en la construcción de una sociedad pacífica y democrática, y en el proceso de desarrollo sostenible y de promoción de la diversidad cultural..." (la negrita es nuestra).

Nótese que en su artículo 2 se contemplan algunas definiciones importantes en relación con lo que debe entenderse por patrimonio cultural:

"Definiciones. A efectos del presente Convenio, por patrimonio cultural se entiende un conjunto de recursos heredados del pasado que las personas identifican, con independencia de a quién pertenezcan, como reflejo y expresión de valores, creencias, conocimientos y tradiciones propios y en constante evolución. Ello abarca todos los aspectos del entorno resultantes de la interacción entre las personas y los lugares a lo largo del tiempo".

Entre estos elementos que definen la noción de patrimonio cultural se observan aquellos que integran la definición inicialmente planteada en este estudio respecto de lo que debe entenderse por DIC. En consecuencia, las previsiones del Convenio Faro antes revisadas también nos conducen a las mismas conclusiones respecto de las previsiones revisadas en el SIDH: el DIC viene a ser un derecho que integra o forma parte del derecho a participar en la vida cultural y que en el SEDH -según las previsiones antes revisadas- se reconoce a todas las personas incluyendo a los migrantes.

$\mathrm{Al}$ igual que lo hicimos respecto de las normas internacionales erigidas en el ámbito universal, una revisión de las previsiones existentes en los ámbitos regionales - tanto en el SIDH como en el SEDH- nos permiten arribar a similares conclusiones: i) en los instrumentos internacionales que integran los ámbitos regionales (SIDH y SEDH) se observa el reconocimiento a todas las personas del derecho a participar de la vida cultural. Ello implica el reconocimiento del DIC, ya que este último viene a ser parte integrante de aquel. Ello amplia la comprensión de la titularidad de este derecho desde los pueblos indígenas y tribales, a otros grupos, como un derecho de carácter general de toda persona. Luego, se fortalece el derecho al ampliar su marco de aplicación como derecho general. (ii) Se plantea el DIC como un derecho dependiente del derecho a la participación en la vida cultural (DESC) y, esta vez, ya no necesariamente como una categoría au-

condiciones apropiadas que permitan expresar, preservar y desarrollar esa identidad; [...] es necesaria la creación de un clima de tolerancia y diálogo para permitir que la diversidad cultural sea una fuente y un factor, no de división, sino de enriquecimiento de cada sociedad". (artículo 4) "1... A este respecto, tendrán debidamente en cuenta las condiciones específicas de las personas pertenecientes a las minorías nacionales. 2. Las medidas adoptadas de conformidad con el apartado 2 no se considerarán un acto de discriminación. (artículo 5) "1. Las partes se comprometen a promover las condiciones necesarias para permitir a las personas pertenecientes a minorías nacionales mantener y desarrollar su cultura, así como preservar los elementos esenciales de su identidad, a saber, su religión, lengua, tradiciones y patrimonio cultural..." (artículo 6) "1. Las partes promoverán un espíritu de tolerancia y de diálogo intercultural, y tomarán medidas eficaces para favorecer el respeto y la comprensión mutuas entre todas las personas que vivan en su territorio, sea cual fuere su identidad étnica, cultural, lingüística o religiosa, en particular en los campos de la educación, de la cultura y de los medios de comunicación. 2. Las Partes se comprometen a tomar las medidas apropiadas para proteger a las personas que puedan ser objeto de amenazas o de actos de discriminación, de hostilidad o de violencia a consecuencia de su identidad étnica, cultural o religiosa". 
tónoma, emergente de la interconexión entre los derechos fundamentales a la igualdad y no discriminación; iii) observamos una ampliación del marco de reconocimiento del DIC para incluir aquí a los migrantes ${ }^{95}$.

\subsection{Identidad cultural de los migrantes y su catalogación como minorías.}

En los ámbitos regionales el DIC también se reconoce en otros instrumentos regionales, pero su aplicación solo se observa respecto de aquellas personas pertenecientes a minorías, bajo parámetros que han de variar dependiendo del sistema de que se trate.

Respecto del SIDH, ya habíamos adelantado la ausencia de prescripiciones normativas textuales relativas al DIC. Es mediante un procedimiento de hermenéutica que se han vinculado sus disposiciones con un conjunto de otros instrumentos de diversa naturaleza, en particular el Protocolo de San Salvador, para asegurar su reconocimiento del derecho a la participación en la vida cultural y, dentro de él, el DIC ${ }^{96}$. Esta argumentación de la Corte IDH y su hermenéutica extensiva, se basa, en las disposiciones generales de la CADH relativas a la obligación de respetar los derechos, el deber de adoptar disposiciones de derecho interno y las normas de interpretación ${ }^{97}$ así como en el marco de las reparaciones ordenadas conforme ese instrumento ${ }^{98}$, tanto en las decisiones propiamente tales, como en los votos particulares de algunos de sus jueces.

En la jurisprudencia emanada de la Corte IDH observamos diversos criterios hermenéuticos relativos a la configuración del derecho DIC. Si bien es cierto que estos han sido dictaminados en el marco de protección de grupos minoritarios (específicamente, pueblos, comunidades indígenas y sus miembros), no es menos cierto que las fuentes de tales pronunciamientos -en concatenación con los argumentos expuestos a lo largo de este estudio- nos autorizan a extender su aplicación respecto de los migrantes, entendiendo a estos como minorías. De hecho, la Corte IDH ha expandido sus criterios en cuanto a la titularidad de este derecho para incorporar a los pueblos afrodescendientes ${ }^{99} \mathrm{y}$ más recientemente a todos los grupos, sosteniendo que el DIC es un derecho que también les alcanza ${ }^{100}$.

\footnotetext{
${ }^{95}$ FAUNDES, Juan Jorge, BUENDÍA, Paloma. Hermenéuticas del derecho humano a la identidad cultural en la jurisprudencia interamericana, un análisis comparado a la luz del ICCAL. Revista Brasileira de Políticas Públicas. Vol. 12, Nº $^{\circ}$.

96 CORTE IDH, "Caso comunidades indígenas miembros de la asociación Lhaka Honhat (nuestra tierra) vs. Argentina", Fondo, reparaciones y costas, sentencia de 6 de febrero de 2020, párr. 231.

97 “Artículo 1. Obligación de Respetar los Derechos 1. Los Estados Partes en esta Convención se comprometen a respetar los derechos y libertades reconocidos en ella y a garantizar su libre y pleno ejercicio a toda persona que esté sujeta a su jurisdicción, sin discriminación alguna por motivos de raza, color, sexo, idioma, religión, opiniones políticas o de cualquier otra índole, origen nacional o social, posición económica, nacimiento o cualquier otra condición social." “Artículo 2. Deber de Adoptar Disposiciones de Derecho Interno... los Estados Partes se comprometen a adoptar, con arreglo a sus procedimientos constitucionales y a las disposiciones de esta Convención, las medidas legislativas o de otro carácter que fueren necesarias para hacer efectivos tales derechos y libertades.” Y, “Artículo 29. Normas de Interpretación. Ninguna disposición de la presente Convención puede ser interpretada en el sentido de: [...] b) limitar el goce y ejercicio de cualquier derecho o libertad que pueda estar reconocido de acuerdo con las leyes de cualquiera de los Estados Partes o de acuerdo con otra convención en que sea parte uno de dichos Estados". Como se observa, la Corte IDH basa su hermenéutica extensiva que aplica ampliamente a los distintos derechos, en los artículos 1.1., 2, 29b y 63, objeto de este apartado.

$98 \mathrm{Al}$ efecto, señala la Convención en su artículo 63: "Cuando decida que hubo violación de un derecho o libertad protegidos en esta Convención, la Corte dispondrá que se garantice al lesionado en el goce de su derecho o libertad conculcados. Dispondrá, asimismo, si ello fuera procedente, que se reparen las consecuencias de la medida o situación que ha configurado la vulneración de esos derechos y el pago de una justa indemnización a la parte lesionada."

99 CORTE IDH, Caso Aloeboetoe y otros Vs. Surinam, 10 septiembre de 1993 (Reparaciones y Costas); CORTE IDH Caso de la Comunidad Moiwana Vs. Suriname, 15 junio de 2005 (Excepciones Preliminares, Fondo, reparaciones y Costas); CORTE IDH, Caso del Pueblo Saramaka vs. Surinam, 28 noviembre de 2007 (Excepciones Preliminares, Fondo, Reparaciones y Costas), párr. 128; CORTE IDH, Caso Comunidad Garífuna de Punta Piedra y sus miembros Vs. Honduras, 8 octubre de 2015, Excepciones Preliminares, Fondo, Reparaciones y Costas; CORTE IDH, Caso Comunidad Garifuna Triunfo de la Cruz y sus miembros vs. Honduras. Fondo, reparaciones y costas, Sentencia 8 de octubre de 2015.

100 CORTE IDH, "Caso comunidades indígenas miembros de la asociación Lhaka Honhat (nuestra tierra) vs. Argentina”, Fondo, reparaciones y costas, sentencia de 6 de febrero de 2020, párrs. 231, 236, 240 (pp. 82-87; B1.1.4; B.1.2, notas 233, 238).
} 
La Corte IDH ha sostenido que el DIC es un derecho fundamental que debe ser respetado en una sociedad multicultural, pluralista y democrática ${ }^{101}$. Esta afirmación identifica el núcleo normativo del derecho que, concretamente, se materializa en el amparo de las formas de vida de los grupos minoritarios, su lengua, mecanismos de resolución de conflictos, religión, formas de organización y toma de decisión, entre otros aspectos. Todo lo cual, en lo jurídico, configura la interdependencia del $\mathrm{DIC}^{102}$ con otros derechos fundamentales, también amparados por la CADH. Además, tales planteamientos implican que la vulneración del DIC se traduce en la violación de los derechos asegurados en la CADH y una afectación a los valores democráticos que sostienen al SIDH.

Asimismo, en relación con la articulación de las fuentes internacionales citadas en los apartados anteriores, que configuran y dotan de contenido al derecho humano a la identidad cultural, fijando sus estándares de cumplimiento - bajo la hermenéutica de la Corte IDH (en especial la noción de corpus iuris)-, ha sostenido que:

“... las normas indicadas deben entenderse y aplicarse de forma armónica con otros compromisos internacionales de los Estados, tales como los que surgen, por ejemplo, del artículo 15 del [PIDESC] y del artículo 27 del [PDCP] o del Convenio 169. Por ello, no corresponde entender que tales normas mandan políticas estatales que propendan a la asimilación de grupos minoritarios, o con pautas culturales propias, a una cultura que se pretenda mayoritaria o dominante. Por el contrario, los mandatos de procurar un desarrollo 'integral', 'incorporar' y acrecentar la 'participación' de sectores poblacionales para su 'plena integración', estimular la cultura y 'preservar y enriquecer' el patrimonio cultural, deben entenderse en el marco del respeto a la propia vida cultural de los diversos grupos..."103.

En relación con las fuentes, la Corte IDH también ha sostenido que el derecho a participar en la vida cultural incluye el DIC, a la luz de la Carta de la OEA (artículos 30, 45 f., 47 y 48) que contiene el compromiso de los Estados para que sus pueblos alcancen un desarrollo integral que abarca "la incorporación y creciente participación de los sectores marginales de la población y en la vida cultural... para estimular la cultura y preservar y enriquecer el patrimonio cultural de los pueblos americanos"104.

De suerte tal que, en la visión jurisprudencial de este tribunal, en general, el ejercicio del derecho humano a la identidad cultural es una expresión del derecho a la participación cultural de toda persona; y, en particular, reconoce el valor de las manifestaciones culturales (inicialmente de los pueblos indígenas y otros grupos afrodescendientes y finalmente de otros grupos, lo que incluye a los migrantes como minorías). Así, la identidad cultural constituye la base material de un conjunto de derechos humanos a los que corresponde amparo, mediante una hermenéutica propia y medidas efectivas, por parte del Estado y, en general, la protección de la diversidad cultural y del DIC se relevan como presupuestos democráticos del SIDH.

En el ámbito europeo, el CEDH - al igual que la $\mathrm{CADH}$ - tampoco considera en su texto de forma expresa el derecho humano a la identidad cultural. Por ello, es necesario tener en consideración la revisión

\footnotetext{
101 CORTE IDH, Caso Pueblo Indígena Kichwa de Sarayaku Vs. Ecuador, Sentencia de 12 junio 2012, párr. 217; CORTE IDH, “Caso comunidades indígenas miembros de la asociación Lhaka Honhat (nuestra tierra) vs. Argentina”, Fondo, reparaciones y costas, sentencia de 6 de febrero de 2020, párr. 231 (Nota 233); CORTE IDH, Caso Comunidad Garífuna de Punta Piedra y sus miembros vs. Honduras. Sentencia de 8 de octubre de 2015. Serie 304-, párr. 158; CORTE IDH, Caso Pueblo Xucuro vs. Brasil (2018), párr. 125; CORTE IDH. Caso Comunidad Indigena Sawhoyamaxa vs. Paraguay, sentencia 29 marzo 2006, párrs. 138, 212; CORTE IDH, Caso Comunidad Indígena Yakye Axa Vs. Paraguay, Fondo, reparaciones y costas, Sentencia 17 de junio de 2005, párr. 143, 149.

102 CORTE IDH, "Caso comunidades indígenas miembros de la asociación Lhaka Honhat (nuestra tierra) vs. Argentina”, Fondo, reparaciones y costas, sentencia de 6 de febrero de 2020. También véase FAUNDES, Juan Jorge, CARMONA, Cristóbal, SILVA, Pedro Pablo. La Corte Interamericana de Derechos Humanos. Hermenéutica del derecho al medio ambiente sano, a la identidad cultural y a la consulta, a la luz de la sentencia "Lhaka Honhat (nuestra tierra) vs. Argentina". Revista Brasileira de Políticas Públicas. Vol. 10, N² 2020. pp. $644-675$.

103 CORTE IDH, "Caso comunidades indígenas miembros de la asociación Lhaka Honhat (nuestra tierra) vs. Argentina", Fondo, reparaciones y costas, sentencia de 6 de febrero de 2020, párr. 231.

104 CORTE IDH, "Caso comunidades indígenas miembros de la asociación Lhaka Honhat (nuestra tierra) vs. Argentina”, Fondo, reparaciones y costas, sentencia de 6 de febrero de 2020. parr. 231.
} 
jurisprudencial del $\mathrm{TEDH}^{105}$ respecto de diversos casos vinculados a derechos culturales de minorías ${ }^{106}$. Esta interpretación hermenéutica se fundamenta en la protección de la vida privada y familiar (art. 8 CEDH); los derechos lingüísticos y educativos (art. 2 del Protocolo $N^{\circ} 1$ ); la libertad de pensamiento, de conciencia y de religión (art. $9 \mathrm{CEDH}$ ), el derecho a la libertad de reunión y asociación (artículo 11 CEDH); y la libertad de expresión (artículo $10 \mathrm{CEDH}$ ). Paralelamente, diversos casos han considerado la discusión de las garantías judiciales del artículo 6.1 del CEDH, en relación con el Derecho a un proceso equitativo.

En lo relativo a los artículos 8 y 14 del CEDH para el tratamiento de las minorías vulnerables, se ha sostenido que los derechos protegidos por los referidos artículos "son indisociables"107. De este modo, podemos observar que los derechos resguardados en los artículos 14 (prohibición de discriminación) y 8 (vida familiar) del CEDH, según la interpretación del TEDH, amparan la identidad étnica de quienes son parte de una minoría nacional y, a su vez, en dicha identidad, protegida por el referido convenio, se encuentran contenidos los elementos propios de la identidad cultural. La prohibición de discriminación (art. 14 CEDH) también se ha asociado con los derechos lingüísticos y educativos (art. 2 del Protocolo $\left.\mathrm{N}^{\circ} 1\right)^{108}$, con la libertad religiosa (Artículo 9 del CEDH) ${ }^{109}$, libertad de asociación y de reunión (Artículo 11 del CEDH) junto a la libertad de expresión (Artículo 10 del CEDH) ${ }^{110}$. Para el TEDH el origen étnico no puede ser causa de discriminación y que muchas veces se deben introducir diferenciaciones, como medidas positivas, para corregir desigualdades fácticas ${ }^{11}$. De este modo se ha reconocido a las minorías, entre otros aspectos, el derecho a: desarrollar libremente las diversas formas de vida tradicional, la libertad de manifestar su religión o sus convicciones, individual o colectivamente, en público o en privado y o con otros, por medio del culto, la enseñanza, las prácticas y la observación de los ritos; la no discriminación en la enseñanza y a que ella se armonice con el uso de la lengua de esas minorías ${ }^{112}$.

\footnotetext{
105 Según el TEDH, el derecho a la identidad cultural es comprendido, indirectamente, entre otros, bajo los artículos 8, que contempla el derecho a vivir de acuerdo con una identidad cultural y el derecho a elegir libremente la identidad cultural, el artículo 9 como derecho a la identidad religiosa, y el artículo 11, que ampara la libertad de asociación bajo un fin cultural (COUNCIL OF EUROPE, 2011, pp. 14-22).

106 En el marco europeo, son relevantes para la protección de este derecho las previsiones del FCNM. Asimismo, en los artículos 7, 8 y 9 el FCNM (1994) asegura el derecho de las personas pertenecientes a minorías a la libertad de reunión, de asociación, de expresión y la de pensamiento, conciencia y religión. En los artículos 10, 11 y 14 el derecho a sus las lenguas minoritarias, en artículo 13 se establecen derechos en materia. Y el artículo 15 dispone que: "Las Partes establecerán las condiciones necesarias para la participación efectiva de las personas pertenecientes a minorías nacionales en la vida cultural, social y económica, así como en los asuntos públicos, en particular los que los afecten."

107 TEDH, Case Buckley v. United Kindom, N²0348/92, sentencia 29 septiembre de 1996. Voto disidente, Juez Petiti. pp. 29, 31. Los primeros antecedentes para la formulación de una interpretación que respetase los derechos de las minorías se observan en algunos votos disidentes que señalaron lo siguiente: "Se ha manifestado ante el Tribunal que la solicitante, como Gitana, tiene los mismos derechos y deberes que todos los demás miembros de la comunidad. Creo que esta es una simplificación excesiva de la cuestión de los derechos de las minorías. Puede que no sea suficiente para prevenir la discriminación que los miembros de grupos minoritarios reciban un trato igual ante la ley. En orden a establecer la igualdad de hecho, puede ser necesario un trato diferente para preservar su patrimonio cultural especial" (TEDH, Case Buckley v. United Kindom, №20348/92, sentencia 29 septiembre de 1996. Voto disidente, Juez Lohmus. p. 26.). Posteriormente, en el 2001 el TEDH operó un modo particular de reconocimiento del derecho humano a la identidad cultural, considerando el derecho a mantener la identidad de una minoría, a llevar su vida privada y familiar conforme con su propia tradición, todo, de acuerdo con el artículo 8 del CEDH (ELOSEGUI ITXACO, María. El concepto jurisprudencial de acomodamiento razonable. Tribunal supremo de Canadá y TEDH ante la gestión de la diversidad cultural y religiosa en el espacio público. Navarra: Editorial Aranzandi, 2013. pp. 22, 230-235).

108 TEDH, Caso D.H. c. República Checa, [GC], Nº57325/00, sentencia 7 de febrero de 2006. parr.176; TEDH, Caso Sampanis y otros c. Grecia, № 32526/05, sentencia 5 de junio de 2008; TEDH, Caso Oršuš y otros c. Croacia, N¹5766/03, sentencia 16 de marzo de 2010. parr. 143.

109 Sobre asuntos relativos al derecho de los padres a la educación religiosas de sus hijos, uso de símbolos religiosos, vestimentas religiosas, véase, TEDH, Laustsiy otros con Italia, N³0814/06, 3 de noviembre de 2009; TEDH, Muñoz Diaz, con España, No49151/07, sentencia 8 de diciembre 2009; TEDH, Caso Leyla Sabin con Turquia, N44774/1998, sentencia 29 junio 2004; TEDH, S.A.S. versus Francia, N43835/2011, (G.S.) sentencia 1 de julio 2014;

110 TEDH, Caso Sidiropolus y otros contra Grecia, N² 26695/95, sentencia 10 de julio 1998; TEDH, Caso Stankov y la Organización Unida de Macedonia Ilinden c. Bulgaria, N²9221/95 y N²9225/95, sentencia 2 de octubre de 2001.

111 TEDH, Asunto Sejdicy Finci c. Bosnia-Herzejovina, N²7996/06 y 34836/06, (GS) sentencia 22 diciembre 2009, párr. 44.

112 v. FAUNDES, Juan Jorge. Diálogo entre la Corte Interamericana de Derechos Humanos y el Tribunal Europeo de Derechos Humanos en torno al Derecho Humano a la Identidad Cultural” Brazilian Journal of International Law. Vol. 11, N 3, pp. 222-
} 
Adicionalmente, el TEDH ha entendido que la diversidad cultural y el pluralismo, son valores basales del orden democrático que resguarda el $\mathrm{CEDH}^{113}$. De este modo, el TEDH - al igual que lo observado por la Corte IDH en el SIDH - también se ha referido respecto de los derechos culturales como un valor relevante en un sistema democrático ${ }^{114}$. El TEDH se ha decantado por reconocer la importancia de la diversidad cultural y el respeto de las culturas de los diferentes grupos, como valor democrático general y al mismo tiempo, ha hecho referencia a la vulnerabilidad de los grupos minoritarios ${ }^{115}$. Ello resulta de interés si tomamos en cuenta que en la sección inicial hicimos también referencia a la asociación existente entre las minorías y la vulnerabilidad, como elementos que caracterizan a los migrantes y que autoriza la inclusión de estos grupos dentro de estas categorías. Esta vulnerabilidad es la que exige a los gobiernos (y al TEDH en su control) una atención especial a las necesidades y al "modo de vida propio" -romaní en este caso-, tanto en la reglamentación general, como en la ponderación de acciones y de decisiones de casos concretos ${ }^{116}$. Esta necesidad de brindar protección a las minorías y grupos vulnerables, su identidad, cultura y modo de vida, aporta en el entendimiento del contenido del DIC como derecho humano y pilar democrático europeo e interamericano.

\section{Conclusiones.}

El derecho humano a la identidad cultural esta imbricado en las libertades inherentes a la dignidad de la persona e integra - en un proceso permanente- la diversidad cultural como valor de las sociedades democráticas. Entendido como un derecho sintesis, considera enlazados el derecho a la identidad y el derecho a la cultura. Sujeto a una reinterpretación constante, los requerimientos del DIC han de diversificarse dependiendo de las necesidades particulares de cada grupo. En el caso de los migrantes, el ejercicio del este derecho - desde una perspectiva colectiva o individual- estará vinculado a sus sistemas de valores, sus creencias, tradiciones y empleo de su idioma. El reconocimiento del DIC ha crecido progresivamente, ganando gran consideración entre los expertos y profesionales de los derechos humanos. No obstante, su protección internacional no se observa contenida en un único instrumento, sino que su configuración y desarrollo progresivo se desprende de la interpretación de diversos tratados, declaraciones y demás convenios internacionales adoptados tanto en el ámbito universal como regional. El estudio propuesto nos ha permitido arribar a las siguientes conclusiones:

En la sección 1.1 de este artículo apuntamos a una interpretación amplia de los diversos instrumentos internacionales que conforman el ámbito universal, a fin de observar la reiterada presencia de prohibiciones de discriminación en relación con el trato que se brinda a los migrantes en lo tocante al ejercicio de sus derechos y libertades fundamentales. Ello se traduce en el deber de reconocimiento por parte de los Estados de las diferencias y particularidades de los migrantes como un elemento de su dignidad personal. Por tanto, estos últimos estarían autorizados a justificar el ejercicio del DIC como derecho humano con base al principio de igualdad y no discriminación.

De acuerdo con los planteamientos de la sección 1.2 de este artículo, el reconocimiento de la identidad cultural a favor de los migrantes - bajo una interpretación estricta de los instrumentos internacionales pro-

\footnotetext{
255. 2020c.

113 TEDH, Asunto Sejdic y Finci c. Bosnia-Herzejovina, N²7996/06 y 34836/06, (GS) sentencia 22 diciembre 2009, párr. 44; TEDH, Laustsi y otros con Italia, N³0814/06, 3 de noviembre de 2009. parr. 56.

114 v. FAUNDES, Juan Jorge. Diálogo entre la Corte Interamericana de Derechos Humanos y el Tribunal Europeo de Derechos Humanos en torno al Derecho Humano a la Identidad Cultural” Brazilian Journal of International Law. Vol. 11, N 3, pp. 222255. 2020c.

115 TEDH, Caso Sampanis y otros c. Grecia, No 32526/05, sentencia 5 de junio de 2008, párrs. 37, 71. También v.: TEDH, Caso Oršuš y Otros c. Croacia, $\mathrm{N}^{\circ} 15766 / 03$, sentencia 16 de marzo de 2010, párr. 77.

116 TEDH, Caso D.H. c. República Checa, [GC], N57325/00, sentencia 7 de febrero de 2006. parr. 181.

Siguiendo el precedente de Chapman contra Reino Unido. v. TEDH, Caso Chapman c. Reino Unido, N²7238/95, (GS) 18 de enero de 2001, párr. 96; Connors contra Reino Unido, núm. 66746/01, 27 de mayo de 2004, párr. 84
} 
pios del sistema universal- subyace en la base de considerarles como pertenecientes a minorías. Aunque no existe un consenso respecto de lo que debe entenderse por minoría y la tipología de estas es bastante extensa, ello no obsta para incluir dentro de ellas a los migrantes como nuevas minorías transnacionales por cumplir con la mayoría de los criterios relevantes para clasificar a un grupo dentro de las nociones más aceptadas al respecto. Así, conforme las fuentes estudiadas, estas nuevas minorías tienen derecho a que se les reconozcan sus particularidades y diferencias, mediante el pleno ejercicio de su derecho humano a la identidad cultural. El Estado está en el deber de asegurar la realización y el ejercicio de este derecho.

La revisión presentada en la sección 2.1 concluye que los instrumentos internacionales que integran los sistemas regionales, europeo e interamericano, reconocen a todas las personas del derecho a participar de la vida cultural.

En particular, la Corte IDH ha ampliado la comprensión de la titularidad de este derecho desde, inicialmente, los pueblos indígenas y tribales, a otros grupos, hasta alcanzar una comprensión del DIC como derecho humano de carácter general, de toda persona, dependiente del derecho a la participación en la vida cultural y no, necesariamente, como una categoría autónoma, emergente de la interconexión entre los derechos fundamentales a la igualdad y no discriminación. Finalmente, en esta sección observamos una ampliación del marco de reconocimiento del derecho humano a la identidad cultural para incluir aquí a los migrantes.

En la sección 2.2 de este estudio observamos que el DIC también se reconoce en otros instrumentos regionales, pero su aplicación solo se observa respecto de aquellas personas pertenecientes a minorías, bajo parámetros que han de variar dependiendo del sistema regional de derechos humanos de que se trate.

En el SIDH el reconocimiento del derecho humano a la identidad cultural se ha logrado mediante un procedimiento de hermenéutica que ha vinculado las disposiciones de la $\mathrm{CADH}$ con un conjunto de otros instrumentos de diversa naturaleza para asegurar el reconocimiento del derecho a la participación en la vida cultural y, dentro de él, el DIC. Si bien es cierto que estos han sido dictaminados en el marco de protección de grupos minoritarios (específicamente, pueblos, comunidades indígenas y sus miembros), las fuentes de tales pronunciamientos - en concatenación con los argumentos expuestos a lo largo de este estudio- autorizan a extender su aplicación respecto de los migrantes considerados como grupos minoritarios culturales. Así lo ha entendido la Corte IDH al expandir sus criterios precedentemente en cuanto a la titularidad de este derecho para incorporar a todos los grupos, sosteniendo que la identidad cultural es un derecho que también les alcanza (caso concreto de los pueblos afrodescendientes).

La Corte IDH ha sostenido que el DIC es un derecho fundamental que debe ser respetado en una sociedad multicultural, pluralista y democrática, lo que identifica el núcleo normativo del derecho que, concretamente, se materializa en el amparo de las formas de vida de los grupos minoritarios, su lengua, mecanismos de resolución de conflictos, religión, formas de organización y toma de decisión, entre otros aspectos. Tales planteamientos implican que la vulneración del DIC de estos grupos minoritarios se traduce en la violación de los derechos humanos asegurados en la CADH y una afectación a los valores democráticos que sostienen al SIDH.

En el ámbito europeo, para el TEDH el origen étnico no puede ser causa de discriminación, por lo que muchas veces se deben introducir diferenciaciones, como medidas positivas, para corregir desigualdades fácticas. Así, tras asociar el derecho a la no discriminación con otros derechos, el TEDH ha reconocido a las minorías, entre otros aspectos, el derecho a: desarrollar libremente las diversas formas de vida tradicional, la libertad de manifestar su religión o sus convicciones, individual o colectivamente, en público o en privado y o con otros, por medio del culto, la enseñanza, las prácticas y la observación de los ritos; la no discriminación en la enseñanza y a que ella se armonice con el uso de la lengua de esas minorías. Ello debiese hacerse extensible a los migrantes por su catalogación como minorías. Asimismo, el TEDH -al igual que lo observado en el SIDH - también se ha referido a la al respecto de los derechos culturales como un valor relevante en un sistema democrático, decantándose por reconocer la importancia de la diversidad cultural y 
el respeto de las culturas de los diferentes grupos, como valor democrático general y al mismo tiempo, ha hecho referencia a la vulnerabilidad de los grupos minoritarios. Ello resulta de interés si tomamos en cuenta que en la sección inicial hicimos también referencia a la asociación existente entre las minorías y la vulnerabilidad, como elementos que caracterizan a los migrantes y que autoriza la inclusión de estos grupos dentro de estas categorías. Esta vulnerabilidad es la que exige a los gobiernos (y al TEDH en su supervisión) una atención especial a las necesidades y al "modo de vida propio" tanto en la reglamentación general, como en la ponderación de acciones y de decisiones de casos concretos.

De esta forma, desde sus fuentes y conforme la jurisprudencia revisada, podemos afirmar la existencia del derecho humano a la identidad cultural de los migrantes, justificada, tanto, en el derecho a la igualdad y no discriminación de los integrantes de las minorías; como en la necesidad de brindar protección a las minorías y grupos vulnerables, su identidad, cultura y modo de vida, en el entendimiento que el derecho humano a la identidad cultural es un valor fundante de las sociedades democráticas.

\section{Referencias.}

AGUILAR, Gonzalo. La dinámica internacional de la cuestión indígena. Santiago: Librotecnia. 2007.

AGUILERA PORTALES, Rafael. Concepto y fundamento de los Derechos Humanos en la teoría jurídica contemporánea. En: AGUILAR CARVALLO, Gonzalo (editor). 60 años después: enseñanzas pasadas y desafíos futuros: Conmemoración de los 60 años de la Declaración Universal de Derechos Humanos y de la Declaración Americana de los Derechos y Deberes del Hombre. Santiago: Librotecnia, 2008. p. 17-75.

ANAYA, James. International human rights and indigenous peoples: the move toward the multicultural state. Arizona Journal of International \& Comparative Law, vol. 21, N $1 \quad$ pp. 13-61. 2004.

ANDRADE, María José. Pueblos indígenas y minorías nacionales: similitudes y diferencias en la protección internacional de sus derechos. Revista Campos en Ciencias Sociales, N6, v. 2, pp. 13-48.

ARP, Jörn, Las minorías nacionales y su protección en Europa. Madrid: Centro de Estudios Políticos y Constitucionales, 2008.

AYSA-LASTRA, Maria; CACHÓN, Lorenzo. Introduction: Vulnerability and Resilience of Latin American Immigrants During the Great Recession. En: AYSA-LASTRA, Maria; CACHÓN, Lorenzo (eds.). Immigrant vulnerability and resilience: Comparative perspectives on Latin American immigrants during the Great Recession. España: Springer. 2015. p. 1-21.

BARROSO, Luis Roberto. La dignidad de la persona humana em el derecho constitucional contemporáneo. La construcción de un concepto jurídico a la luz de la jurisprudencia mundial. Traducción Simone Nevares. Bogotá: Universidad del Externado de Colombia, 2014.

BASCH, Nina; GLICK SCHILLER, Linda; SZANTON BLANC, Cristina. Nations Unbound: Transnational Project, Postcolonial Predicaments, and De-territorialized Nation States. New York: Routledge, 1993.

BENHABIB, Seyla. The claims of culture: equality and diversity in the global era. New Yersey: Princeton university press, 2002.

BLACKWELL Maylei; HERNÁNDEZ, Rosalva; HERRERA, Juan; MACLEOD, Morna; RAMÍREZ, Renya; SIEDER, Rachel; SIERRA, María; SPEED, Shannon. Cruces de fronteras, identidades indígenas, género y justicia en las Américas. Desacatos, Nº 31, p. 13-34, sep./dic. 2009.

BENNOUNE, Karima. Informe de la Relatora Especial sobre los derechos culturales, documento de las Naciones Unidas A/HRC/31/59, 2016. Disponible en: https://undocs.org/es/A/HRC/31/59. Acceso: 10 dic. 2020. 
BUSTAMANTE, Jorge. Un marco de referencia acerca de la vulnerabilidad de los migrantes como sujetos de los derechos humanos. Taller sobre mejores prácticas en materia de migración. CEPAL, 2000.

BUSTAMANTE, Jorge. Informe del Relator Especial sobre los derechos humanos de los migrantes, documento de las Naciones Unidas A/HRC/14/30, 2010. Disponible en: https://undocs.org/es/A/ HRC/14/30. Acceso: 4 oct. 2020.

CASTILLO, Luis. La relación entre los ámbitos normativos internacional y nacional sobre derechos humanos. Estudios Constitucionales, vol. 10, No 2, p. 231-280. 2012.

CORREA, Juan José. Identidades, arraigos y soberanías. Migración peruana en Santiago de Chile. Polis Revista Latinoamericana, vol. 14, № 42, p. 167-189. 2015.

CAPOTORI, Francesco. Study on the rights of persons belonging to ethnic, religious and linguistic minorities, documento de las Naciones Unidas E/CN.4/Sub.2/384/Rev.1, 1979. Disponible en: https://digitallibrary.un.org/record/10387?ln=en. Acceso: 15 may. 2021.

CRÉPEAU, François. Derechos humanos de los migrantes: Informe del Relator Especial sobre los derechos humanos de los migrantes, documento de las Naciones Unidas A/69/302, 2014. Disponible en: https:// documents-dds-ny.un.org/doc/UNDOC/GEN/N14/501/99/PDF/N1450199.pdf?OpenElement. Acceso: 13 mar. 2020.

COMISIÓN INTERAMERICANA DE DERECHOS HUMANOS. Informe sobre Terrorismo y Derechos Humanos, documento de la Organización de los Estados Americanos OEA/Ser.L/V/ll.116, 2002. Disponible en: http://www.acnur.org/fileadmin/scripts/doc.php?file=fileadmin/Documentos/ BDL/2002/1975, Acceso: 10 mar. 2021.

COMISIÓN EDH, G. and E. v. Norway (“Hhe Alta Case”), N 9278/81 y 9415/81, admisibilidad, decisión 3 octubre de 1983.

COMITÉ DE DERECHOS HUMANOS. Observación General No. 15, Comentarios generales adoptados por el Comité de los Derechos Humanos, la situación de los extranjeros con arreglo al Pacto, documento de las Naciones Unidas HRI/GEN/1/Rev.7, 1986. Disponible en: http:/ /hrlibrary.umn.edu/hrcommittee/ Sgencom15.html. Acceso: 3 nov. 2020.

COMITÉ DE DERECHOS HUMANOS. Observación general 21: Trato humano de las personas privadas de libertad (artículo 10), documento de las Naciones Unidas HRI/GEN/1/Rev.9, 1992. Disponible en: https://conf-dts1.unog.ch/1\%20SPA/Tradutek/Derechos_hum_Base/CCPR/00_2_obs_grales_Cte\%20 DerHum\%20\%5BCCPR\%5D.html\#GEN21. Acceso: 2 ene. 2021.

COMITÉ DE DERECHOS HUMANOS. Observación general No 23: Derecho de las minorías (artículo 27), documento de las naciones unidas HRI/GEN/1/Rev.9 (Vol. I), 1994. Disponible en: https://undocs. org/es/HRI/GEN/1/Rev.9(Vol.I). Acceso: 30 jul. 2021.

COMITÉ DE DERECHOS HUMANOS. Observación General No. 31: Naturaleza de la obligación jurídica general impuesta a los Estados Parte en el Pacto, documento de las Naciones Unidas CCPR/C/21/ Rev.1/Add.13, 2004. Disponible en http://www.refworld.org/cgi-bin/texis/vtx/rwmain/opendocpdf. pdf ?reldoc $=$ y\&docid $=478$ b26ea 2 . Acceso: 8 sep. 2021.

COMITÉ DE DERECHOS ECONÓMICOS, SOCIALES Y CULTURALES. Observación general N 21: Derecho de toda persona a participar en la vida cultural (artículo 15, párrafo 1 a), del Pacto Internacional de Derechos Económicos, Sociales y Culturas, documento de las Naciones Unidas E/C.12/GC/21/Rev.1, 2009. Disponible en: https://undocs.org/es/E/C.12/GC/21. Acceso: 3 oct. 2021. parr. 9).

COMITÉ DE PROTECCIÓN DE LOS DERECHOS DE TODOS LOS TRABAJADORES MIGRATORIOS Y DE SUS FAMILIARES. Observación general $\mathrm{N}^{\circ} 2$ sobre los derechos de los trabajadores 
migratorios en situación irregular y de sus familiares, documento de las Naciones unidas CMW/C/GC/2, 2013. Disponible en: https://undocs.org/es/CMW/C/GC/2. Acceso: 4 oct. 2020.

COMITÉ PARA LA ELIMINACIÓN DE LA DISCRIMINACIÓN RACIAL. Recomendación General $\mathrm{N}^{\mathrm{o}} 30$ relativa a la discriminación contra los no ciudadanos, 2004. Disponible en: https:/ /www.refworld.org. es/docid/5d7fc37ca.html. Acceso: 30 may. 2021.

CORTE IDH. Opinión Consultiva OC-18/03 sobre Condición Juridica y Derechos de los Migrantes Indocumentados (2003), 17 septiembre 2003, Serie A No 18.

CORTE IDH. Resolución 2/11 sobre la Situación de los Detenidos de la Bahía de Guantánamo, Estados Unidos, Medidas Cautelares 259-02, 2002. disponible en https://www.cidh.oas.org/pdf\%20files/ Resoluci\%C3\%B3n\%20 2-11\%20Guant\%C3\%A1namo.pdf. Acceso: 5 abr. 2021.

CORTE IDH, Caso Aloeboetoe y otros Vs. Surinam, 10 septiembre de 1993. Reparaciones y Costas.

CORTE IDH Caso de la Comunidad Moiwana Vs. Suriname, 15 junio de 2005. Excepciones Preliminares, Fondo, reparaciones y Costas.

CORTE IDH, Caso Comunidad Indígena Yakye Axa Vs. Paraguay, Sentencia de 17 de junio de 2005. Fondo, Reparaciones y Costas.

CORTE IDH. Caso Comunidad Indígena Sawhoyamaxa Vs. Paraguay, sentencia 29 marzo 2006. Fondo, Reparaciones y Costas.

CORTE IDH, Caso del Pueblo Saramaka Vs. Surinam, 28 noviembre de 2007. Excepciones Preliminares, Fondo, Reparaciones y Costas.

CORTE IDH, Caso Pueblo Indígena Kichwa de Sarayaku Vs. Ecuador, Sentencia de 12 junio 2012. Fondo, reparaciones y costas.

CORTE IDH, Caso Comunidad Garífuna de Punta Piedra y sus miem $\neg$ bros Vs. Honduras, Sentencia de 8 octubre de 2015, Excepciones Preliminares, Fondo, Reparaciones y Costas.

CORTE IDH, Caso Pueblo Xucuro Vs. Brasil, Sentencia de 5 de febrero de 2018. Excepciones Preliminares, Fondo, Reparaciones y Costas.

CORTE IDH, "Caso comunidades indígenas miembros de la asociación Lhaka Honhat (nuestra tierra) Vs. Argentina”, sentencia de 6 de febrero de 2020. Fondo, reparaciones y costas.

DESCHENES, Jules. Proposal concerning a definition of the term "minority", documento de las Naciones unidas E/CN.4/Sub.2/1985/31, 1985. Disponible en: https://digitallibrary.un.org/record/88267?ln=en. Acceso: 7 agosto 2021.

DE LUCAS, Javier. Europa. Derechos, Culturas. Valencia: PUV, Tirant lo Blanch, 2006.

DEL CARPIO, Columba. Pluralismo Jurídico, derecho humano a la identidad cultural y globalización. Navarra: Editorial Aranzadi SA, 2014.

DEL REAL, Alberto. El DIC: ¿derecho de la persona o derecho de los pueblos? Pamplona: Editorial Aranzadi S.A., 2014.

DIÈNE, Doudou; MCDOUGALL, Gay. Promoción y protección de todos los derechos humanos, civiles, políticos, económicos, sociales y culturales, incluido el derecho al desarrollo/racismo, discriminación racial, xenofobia y formas conexas de intolerancia: seguimiento y aplicación de la declaración y programa de acción de Durban, documento de las Naciones Unidas A/HRC/7/19/Add.5 y A/HRC/7/23/Add.3 (Informe conjunto), 2008. Disponible en: https://undocs.org/sp/A/HRC/7/19/Add.5. Acceso: 12 abril 2021. 
DONDERS, Yvonne. Towards a Right to Cultural Identity? Yes, Indeed! Diritti umani y diritto internazionale, vol 12, $\mathrm{N}^{\circ}$ 5, p. 525-548. 2018.

ELOSEGUI ITXACO, María. El concepto jurisprudencial de acomodamiento razonable. Tribunal supremo de Canadá y TEDH ante la gestión de la diversidad cultural y religiosa en el espacio público. Navarra: Editorial Aranzandi, 2013.

FAUNDES, Juan Jorge. Derecho fundamental a la identidad cultural de los pueblos indígenas: un nuevo paradigma en la defensa penal indígena en Chile frente al Estado de Derecho hegemónico. Revista Izquierdas, $\mathrm{N}^{\circ} 45$, p. 51-78. 2019a.

FAUNDES, Juan Jorge. El derecho fundamental a la identidad cultural de los pueblos indígenas: un derecho matriz y filtro hermenéutico para las constituciones de América Latina: la justificación. Revista Brasileira de Políticas Públicas, vol. 9, No 2, p. 513-535. 2019b.

FAUNDES, Juan Jorge. El derecho fundamental a la identidad cultural de los pueblos indígenas, configuración conforme el derecho internacional y perspectivas de su recepción en Chile. Revista Ius et Praxis, vol. 26, No 1, p. 77-100. 2020a.

FAUNDES, Juan Jorge. Horizontes Constituyentes. Reconocimiento de los pueblos indígenas en América Latina: los casos de Chile y Bolivia. Curitiba: Editora Appris, 2020b.

FAUNDES, Juan Jorge. Diálogo entre la Corte Interamericana de Derechos Humanos y el Tribunal Europeo de Derechos Humanos en torno al Derecho Humano a la Identidad Cultural" Brazilian Journal of International Law . Vol. 11, N 3, pp. 222-255. 2020c.

FAUNDES, Juan Jorge, BUENDÍA, Paloma. Hermenéuticas del derecho humano a la identidad cultural en la jurisprudencia interamericana, un análisis comparado a la luz del ICCAL. Revista Brasileira de Políticas Públicas. Vol. 12, N².

FAUNDES, Juan Jorge; RAMÍREZ, Silvina (Eds.). Derecho fundamental a la identidad cultural, abordajes plurales desde América Latina. Santiago: RIL, 2020.

FAUNDES, Juan Jorge, CARMONA, Cristobal, SILVA, Pedro Pablo. La Corte Interamericana de Derechos Humanos. Hermenéutica del derecho al medio ambiente sano, a la identidad cultural y a la consulta, a la luz de la sentencia "Lhaka Honhat (nuestra tierra) vs. Argentina". Revista Brasileira de Políticas Públicas. Vol. 10, N², 2020.

FAUNDES, Juan Jorge; MELLO, Patricia. Grupos vulnerables. En: PIZZI, Jovino; CENSI, Maximiliano (Coordinadores). Glosario de Patologías Sociales. Pelotas: Ufpel, 2021. p. 104-115.

FERRER, Luis Gabriel. La Convención Internacional sobre la Eliminación de Todas las Formas de Discriminación Racial (FASCÍCULO 5). En: COMISIÓN NACIONAL DE LOS DERECHOS HUMANOS (editores). Colección del Sistema Universal de protección de los Derechos Humanos. México: Comisión Nacional de los Derechos Humanos, 2012, p. 1- 88.

GHOSH, Bimal. Derechos humanos y migración: el eslabón perdido. MORÁN QUIROZ, Luis (trad.). México: Red Internacional de Migración y Desarrollo Zacatecas, 2008.

GRIGORY IVANOVITCH, Tunkin. Droit international public: problèmes thèoriques. Paris: Editions A. Pedone, 1965.

GROS ESPIELL, Héctor. La Organización Internacional del Trabajo y los derechos humanos en América Latina. México: UNAM, 1978.

GROSS ESPIELL, Héctor. La dignidad humana en los instrumentos internacionales sobre los derechos humanos. Anuario de Derechos Humanos, vol. 7, N 1, p. 193-224. 2003. 
GRUPO DE TRABAJO SOBRE LAS MINORIAS. Comentario del grupo de trabajo sobre las minorías acerca de la declaración sobre los derechos de las personas pertenecientes a minorías nacionales o étnicas, religiosas y lingüísticas, documento de las Naciones Unidas E/CN.4/Sub.2/AC.5/2005/2, 2005. Disponible en: file:///C:/Users/56931/Downloads/E_CN.4_Sub.2_AC.5_2005_2-ES.pdf. Acceso: 11 jul. 2021.

GUDMUNDUR, Alfredsson; TURK, Danilo. International mechanisms for the monitoring and protection of minority rights: Their advantages, disadvantages and interrelationships. En: BLOED, Arie (ed.). Monitoring human rights in Europe: comparing international procedures and mechanisms. Kluwer: Norwell MA, 1993. p. $169-86$.

GONZALES CAMPOS, Julio, SÁNCHEZ RODRÍGUEZ, Luis Ignacio y SÁENZ DE SANTA MARÍA, Paz Andrés. Curso de derecho internacional público. Madrid: Civitas, 2002.

HABERMAS, Jürgen. El concepto de dignidad humana y la utopía realista de los derechos humanos. Diánoia, vol. LV, p. 3-25. 2010.

HERNÁNDEZ, Rosalva; HERRERA, Juan; MACLEOD, Morna; RAMÍREZ, Renya; SIEDER, Rachel; SIERRA, María; SPEED, Shannon. Cruces de fronteras, identidades indígenas, género y justicia en las Américas. Desacatos, N 31, p. 13-34, septiembre/diciembre. 2009.

HÛBNER, Jorge. Panorama de los derechos humanos. Santiago: Editorial Andrés Bello. 1973. p. 19.

KAZTMAN, Rubén. Notas sobre la medición de la vulnerabilidad social. En: BID-Banco Mundial-CEPALIDEC. $5^{\circ}$ Taller Regional. La medición de la pobreza: métodos y aplicaciones (continuación). Santiago de Chile: CEPAL, 2000. p. 275-301.

KYMLICKA, Will. La evolución de las normas europeas sobre los derechos de las minorías: los derechos a la cultura, la participación y la autonomía. Revista Española de Ciencia Política, N 17, p. 11-50, oct. 2007.

MARIÑO, Fernando; FERNÁNDEZ Carlos. Introducción y aproximación a la noción de persona y grupo vulnerable en el derecho europeo. En: FERNÁNDEZ, Liesa; MARIÑO, Fernando (coord.). La protección de las personas y grupos vulnerables en el derecho europeo. Madrid: Universidad Carlos III de Madrid, 2001.

MECANISMO DE EXPERTOS SOBRE LOS DERECHOS DE LOS PUEBLOS INDÍGENAS. Estudio sobre el papel de los idiomas y la cultura en la promoción y protección de los derechos y la identidad de los pueblos indígenas, documento de las Naciones Unidas A/HRC/EMRIP/2012/3. 2012. Disponible en: https://undocs.org/es/A/HRC/EMRIP/2012/3. Acceso: 10 dic. 2020.

MEDDA-WINDISCHER, Roberta. Fundamentos para la protección de las antiguas y nuevas minorías. En: RUIZ, Eduardo; URRUTIA, Gorka (eds.). Gestión de la diversidad en sociedades tradicionalmente divididas: Derechos humanos en contextos multiculturales. ¿Acomodo de derechos o derechos de acomodo? Bilbao: Instituto de Derechos Humanos, 2010. p. 67-98.

MELLO, Patricia. Constitucionalismo, Transformação e Resiliência Democrática no Brasil: o Ius Constitucionale Commune na América Latina tem uma contribuição a oferecer?. Revista Brasileira Políticas Públicas, vol. 9, No2, p. 254-286. 2019.

MELLO Patricia; LACERDA Clara. El derecho fundamental a la identidad cultural y el constitucionalismo en red en la jurisprudencia del Supremo Tribunal Federal de Brasil. En: FAUNDES, Juan Jorge; RAMÍREZ, Silvinba (Eds.). Derecho fundamental a la identidad cultural, abordajes plurales desde América Latina. Santiago: RIL, 2020.

MARÍN, Ma Luisa. La dignidad humana, los Derechos Humanos y los Derechos Constitucionales. Revista de Bioética y Derecho, N 9, p.1-8. 2007. 
MORA CASTRO, Alberto. Inmigración, participación y estrategias de intervención en el ámbito de la salud: mediación intercultural, intervención psicosocial y promoción de derechos. En: DE LUCAS, Javier; SOLANGES Ángeles (eds.). La igualdad en los derechos: claves de la integración. España: Dykinson, 2009. p. 209-235.

MURPHY, Sean. Principles of International Law. Washington: Thomson West, 2006. pp. 320-326.

OLIVARES, Alberto. El Derecho a la identidad cultural. En: AGUILAR, Gonzalo (Coordinador). Nuevos derechos para una nueva Constitución. Valencia: Tirant Lo Blanch. 2019. pp, 175-190.

OIM. respuestas presentadas por la Organización Internacional para la Migraciones (OIM) a algunas de las preguntas realizadas por la honorable Corte Interamericana de Derechos Humanos, durante la audiencia realizada en el marco de la solicitud de opinión Consultiva sobre niñez migrante los días 9 y 10 de octubre de 2013, documento de la OIM DR/CDH/091, 2013. Disponible en: https://www.corteidh.or.cr/sitios/ Observaciones/complementarias/escrito-OIM-14-11-2013.pdf. Acceso: 4 sep. 2021.

ONU. Conferencia mundial contra el racismo, la discriminación racial, la xenofobia y las formas conexas de Intolerancia, documento de la Organización de Naciones Unidas A/CONF.189/PC.2/7, 2001. Disponible en: https://undocs.org/es/A/CONF.189/PC.2/7. Acceso: 10 dic. 2020.

ORGANIZACIÓN INTERNACIONAL PARA LAS MIGRACIONES. Glosario sobre migración, 2006. Disponible en: http://publications.iom.int/system/files/pdf/iml_7_sp.pdf. Acceso: 3 mar. 2017.

PALACIOS TREVIÑO, Jorge. Los derechos humanos de los trabajadores migratorios y sus familias. En: OEA (editor). Universalismo y Regionalismo a Inicios del Siglo XXI. Río de Janeiro: OEA, 2010. p. 427-452.

PÉREZ-PRAT Luis. Inmigración y Derecho Internacional: ¿un acuerdo imposible? En: Curso de Derechos Humanos de Donostia-San Sebastián, vol. 7. Bilbao: Universidad del País Vasco, 2007. p. 137-164.

RAMÍREZ, Silvina. Igualdad como Emancipación: los Derechos Fundamentales de los Pueblos indígenas. En: MARCELO ALEGRE, Marcelo; GARGARELLA, Roberto (coordinadores). El Derecho a la Igualdad, aportes para un Constitucionalismo Igualitario. Buenos Aires: Abeledo-Perrot, 2012. p. 30-50.

REMIRO BROTÓNS, Antonio. Derecho Internacional Público: Tomo I. Principios fundamentales. Madrid: Tecnos, 1987.

RODRÍGUEZ VIGNOLI, Jorge. Vulnerabilidad y grupos vulnerables: un marco de referencia conceptual mirando a los jóvenes, 2001. Disponible en: https://www.cepal.org/sites/default/files/publication/ files/7150/S018659_es.pdf. Acceso: 18 sep. 2021.

RUIZ CHIRIBOGA, Oswaldo. El DIC de los pueblos indígenas y las minorías nacionales: una mirada desde el sistema interamericano. Revista Internacional de Derechos Humanos, vol. 5, p. 43-69. 2006.

RUIZ, Eduardo. Minorías Europeas y Estado de Derecho. En: GARCÍA RODRÍGUEZ, Isabel (ed.). Las Minorías en una Sociedad Democrática y Pluricultural. Madrid; Universidad de Alcalá, 2001. p. 51-90.

SARMENTO, Daniel. Dignidade da pessoa humana conteúdo, trajetórias e metodologia. Belo Horizonte: Fórum, 2016;

SHAHEED, Farida. Report of the independent expert in the field of cultural rights, Ms. Farida Shaheed, submitted pursuant to resolution 10/23 of the Human Rights Council, documento de las Naciones Unidas A/HRC/14/36. 2010. Disponible en: https://undocs.org/pdf?symbol=en/A/HRC/14/36. Acceso: 10 dic. 2020.

SHAHEED, Farida. Informe de la Relatora Especial sobre los derechos culturales, documento de las Naciones Unidas A/67/287, 2012. Disponible en: https://undocs.org/es/A/67/287. Acceso: 3 oct. 2021.

SHAW, Malcolm. International Law. $6^{a}$ edición. Cambridge: Cambridge University Press, 2008. pp. 304-341. 
SOLÉ, Carlota; PARELLA, Sònia; ALARCÓN, Amado; BERGALLI, Valeria; GIBERT, Francesc. El impacto de la inmigración en la sociedad receptora. Revista Española de Investigaciones Sociológicas, España, 90, p. 31-157. 2000.

SORIANO DÍAZ, Ramón Luis. Los Derechos de las Minorías. Madrid: Editorial Mad, 1999.

SUBIRATS, Joan. Pobreza y Exclusión Social: Un análisis de la realidad española y europea: Colección Estudios Sociales. Barcelona: Fundación La Caixa, 2004.

TEDH, Case Buckley c. United Kindom, N²0348/92, 29 septiembre de 1996.

TEDH, Caso Sidiropolus y otros c. Grecia, N²6695/95, 10 de julio 1998.

TEDH, Caso Chapman c. Reino Unido, N²7238/95, (GS) 18 de enero de 2001.

TEDH, Caso Stankov y la Organización Unida de Macedonia Ilinden c. Bulgaria, $N^{\circ}$ 29221/95 y N 29225/95, 2 de octubre de 2001.

TEDH, Connors c. Reino Unido, núm. 66746/01, 27 de mayo de 2004.

TEDH, Caso Leyla Sahín c. Turquía, N44774/1998, 29 de junio de 2004.

TEDH, Caso D.H. c. República Checa, [GC], No57325/00, 7 de febrero de 2006.

TEDH, Caso Sampanis y otros c. Grecia, No 32526/05, 5 de junio de 2008.

TEDH, Laustsi y otros c. Italia, N³0814/06, 3 de noviembre de 2009.

TEDH, Muñoz Díaz c. España, Nº49151/07, 8 de diciembre de 2009.

TEDH, Asunto Sejdic y Finci c. Bosnia-Herzejovina, N²7996/06 y 34836/06, (GS) sentencia 22 de diciembre 2009.

TEDH, Caso Oršuš y otros c. Croacia, N¹5766/03, sentencia 16 de marzo de 2010.

TEDH, S.A.S. c. Francia, N43835/2011, (G.S.) sentencia 1 de julio de 2014.

TONIATTI, Roberto. Los derechos del pluralismo cultural en la Nueva Europa. R.V.A.P., No. 58, vol. 2, p. $17-48.2000$.

TONIATTT, Roberto. El paradigma constitucional de la inclusión de la Diversidad cultural: notas para una comparación Entre los modelos de protección de las minorías Nacionales en europa y de los pueblos indígenas en Latino américa. 2015 Disponible en: http://www.jupls.eu/images/JPs_WP_RT_Ponencia_2015. pdf. Acceso: 3 oct. 2021.

VALLS, Ramón. El concepto de dignidad humana. Revista de Bioética y Derecho, N 5, p. 278-285. 2015. p. 283-285).

VENTURA-ROBLES, Manuel. Jurisprudencia de la Corte Interamericana de Derechos Humanos en materia de derechos económicos, sociales y culturales. Revista Instituto Interamericano de Derechos Humanos, vol. 40, p. 87-131. 2004. 
Para publicar na revista Brasileira de Políticas Públicas, acesse o endereço eletrônico www.rbpp.uniceub.br

Observe as normas de publicação, para facilitar e agilizar o trabalho de edição. 